\title{
Laminarly Orthogonal Excitation of Fast-Spiking and Low-Threshold-Spiking Interneurons in Mouse Motor Cortex
}

\author{
Alfonso J. Apicella, ${ }^{1}$ Ian R. Wickersham, ${ }^{2}$ H. Sebastian Seung, ${ }^{2}$ and Gordon M. G. Shepherd ${ }^{1}$ \\ ${ }^{1}$ Department of Physiology, Feinberg School of Medicine, Northwestern University, Chicago, Illinois 60611, and ${ }^{2}$ Howard Hughes Medical Institute and \\ Department of Brain and Cognitive Sciences, Massachusetts Institute of Technology, Cambridge, Massachusetts 02139
}

In motor cortex, long-range output to subcortical motor circuits depends on excitatory and inhibitory inputs converging on projection neurons in layers 5A/B. How interneurons interconnect with these projection neurons, and whether these microcircuits are interneuron and/or projection specific, is unclear. We found that fast-spiking interneurons received strong intralaminar (horizontal) excitation from pyramidal neurons in layers 5A/B including corticostriatal and corticospinal neurons, implicating them in mediating disynaptic recurrent, feedforward, and feedback inhibition within and across the two projection classes. Low-threshold-spiking (LTS) interneurons were instead strongly excited by descending interlaminar (vertical) input from layer $2 / 3$ pyramidal neurons, implicating them in mediating disynaptic feedforward inhibition to both projection classes. Furthermore, in a novel pattern, lower layer $2 / 3$ preferentially excited interneurons in one layer (5A/LTS) and excitatory neurons in another (5B/corticospinal). Thus, these inhibitory microcircuits in mouse motor cortex follow an orderly arrangement that is laminarly orthogonalized by interneuron-specific, projection-nonspecific connectivity.

\section{Introduction}

Output signals produced in motor cortex in association with movements are conveyed to downstream motor circuits via the long-range axons of subcortically projecting pyramidal neurons in layers $5 \mathrm{~A}$ and $5 \mathrm{~B}$, particularly corticospinal (Betz cells) and corticostriatal neurons. Excitatory and inhibitory inputs to these projection neurons thus directly influence cortical output. Inhibitory microcircuits, such as intracortical recurrent inhibition between corticospinal neurons, are proposed to mediate specific aspects of motor function (Phillips, 1959; Stefanis and Jasper, 1964a,b; Keller, 1993; Merchant et al., 2008; Isomura et al., 2009; Georgopoulos and Stefanis, 2010; Kaufman et al., 2010; Tanaka et al., 2011).

Corticospinal and other pyramidal neurons in layers $5 \mathrm{~A}$ and $5 \mathrm{~B}$ receive lateral excitatory input from these layers and descending input from layer 2/3 (Kaneko et al., 2000; Weiler et al., 2008; Anderson et al., 2010; Hooks et al., 2011; Kiritani et al., 2012). These excitatory microcircuits are hierarchically organized through layer- and projection-specific connections (Anderson et al., 2010; Hooks et al., 2011; Kiritani et al., 2012). Inhibitory

\footnotetext{
Received Jan. 2, 2012; revised March 27, 2012; accepted April 4, 2012.

Author contributions: A.J.A. and G.M.G.S. designed research; A.J.A. performed research; I.R.W. and H.S.S. contributed unpublished reagents/analytic tools; A.J.A. analyzed data; A.J.A., I.R.W., and G.M.G.S. wrote the paper.

This work was supported by The Simons Foundation (G.M.G.S.), The Whitehall Foundation (G.M.G.S.), National Institute of Neurological Disorders and Stroke-National Institutes of Health Grant NSO61963 (G.M.G.S.), and the Howard Hughes Medical Institute (I.R.W., H.S.S.). We thank T. Kiritani and B. Suter for valuable input, M. Scanziani for helpful discussions, and C. T. Anderson and P. L. Sheets for comments on this manuscript. We are grateful to K. Cosgrove, J. Lübke, and I. Marchionni for help with morphology.

Correspondence should be addressed to Dr. Gordon M. G. Shepherd, Morton 5-660, 303 East Chicago Avenue, Chicago, IL 60611. E-mail: g-shepherd@northwestern.edu.

DOI:10.1523/JNEUROSCI.0011-12.2012

Copyright $\odot 2012$ the authors $\quad 0270-6474 / 12 / 327021-13 \$ 15.00 / 0$
}

inputs to (unlabeled) pyramidal neurons are mainly intralaminar (Kätzel et al., 2011), consistent with the intralaminar inhibitory innervation observed in other cortices (Beierlein et al., 2003; Thomson and Lamy, 2007; Brill and Huguenard, 2009; Fino and Yuste, 2011; Packer and Yuste, 2011). Corticospinal neurons receive inhibition from fast-spiking (FS) and low-thresholdspiking (LTS) interneurons (Tanaka et al., 2011), consistent with inhibitory innervation of projection neurons in other cortical areas and species (Beierlein et al., 2003; Morishima and Kawaguchi, 2006; Kapfer et al., 2007; Silberberg and Markram, 2007; Thomson and Lamy, 2007; Brill and Huguenard, 2009; Fino and Yuste, 2011; Kätzel et al., 2011).

Previous studies show considerable selectivity in excitatory inputs to inhibitory interneurons (Brown and Hestrin, 2009; Fishell and Rudy, 2011; Krook-Magnuson et al., 2012), but comparable knowledge about connectivity in mouse motor cortex is lacking. Are sources of excitation common to FS and LTS interneurons, or interneuron specific? Is excitation mostly intralaminar (as for inhibitory inputs to pyramidal neurons) or multilaminar (as for excitatory inputs to pyramidal neurons)? Is intralaminar excitatory input projection specific or nonspecific?

Here, we addressed these questions by characterizing the functional organization of excitatory synaptic inputs to inhibitory interneurons and their contribution to the inhibitory inputs onto projection neurons (i.e., pyramidal/interneuron microcircuits), focusing on interneurons and projection neurons in layers $5 \mathrm{~A} / \mathrm{B}$. Because of the heterogeneity of neocortical interneurons (DeFelipe, 1997; Markram et al., 2004; Rudy et al., 2011), we used mice expressing GFP in parvalbumin-expressing (FS) and somatostatin-expressing (LTS) interneurons, likely representing the most abundant classes in layers 5A/B of mouse cortex (Gon- 
char et al., 2007; Xu et al., 2010; Rudy et al., 2011). We used photostimulation-based electroanatomical and optogenetic methods, tools with high efficiency and selectivity, permitting measurement of overall (aggregate) connectivity in microcircuits (i.e., rapid assessment of interconnectivity between defined classes of neurons at the population level). We mapped synaptic pathways onto FS and LTS interneurons, and also onto and from corticostriatal and corticospinal neurons. Our findings delineate two distinct laminar inhibitory microcircuits converging on both classes of projection neurons.

\section{Materials and Methods}

Animals. Wild-type C57BL/6, G42 [CB6-Tg(Gad1-EGFP)G42Zjh/J] (Chattopadhyaya et al., 2004), and GIN [FVB-Tg(GadGFP)45704Swn/J] (Oliva et al., 2000) mice of either sex (The Jackson Laboratory) were used for experiments. Animal studies were approved by the Northwestern University Animal Care and Use Committee and conformed to the animal welfare guidelines of the National Institutes of Health and Society for Neuroscience.

Retrograde labeling. Following published methods (Anderson et al., 2010), fluorescent microspheres (RetroBeads; Lumafluor) were injected into the dorsolateral striatum or cervical spinal cord of P18-P21 mice to label corticostriatal or corticospinal neurons. Corticospinal neurons were labeled by injecting beads into the spinal cord at the cervical level 2, $0.2-1 \mathrm{~mm}$ lateral to the midline and $0.5-1 \mathrm{~mm}$ deep. Contralaterally projecting corticostriatal neurons in motor cortex were selectively labeled by stereotaxically $(1.5-2.0 \mathrm{~mm}$ posterior and $3.5 \mathrm{~mm}$ lateral to bregma) pressure injecting (Picospritzer III; Parker Hannifin) $\sim 25 \mathrm{nl}$ of green or red fluorescent microspheres in the left dorsolateral striatum. The glass pipette was advanced into the dorsolateral striatum at an angle $\sim 17^{\circ}$ off the sagittal plane and $\sim 42^{\circ}$ off the horizontal plane, penetrating to a depth of $3.5 \mathrm{~mm}$ from the surface of the brain. For convenience, we henceforth refer to these contralaterally projecting (i.e., intratelencephalic-type) corticostriatal neurons as "corticostriatal neurons," which are distinct from the pyramidal tract-type projection neurons that project only ispilaterally to the striatum (en route to brainstem and/or spinal targets) (Reiner et al., 2010).

Slice preparation. Experiments involving only retrograde labeling of neurons were performed at a postnatal age of P22-P28. Those involving genetically labeled interneurons were performed at a slightly younger age range (P18-P25) to facilitate identification and recording from labeled interneurons. Mice were killed by decapitation under isoflurane anesthesia. Brains were dissected and sectioned in ice-cold, carbogenated choline solution (in mM: 110 choline chloride, $25 \mathrm{NaHCO}_{3}, 2.5 \mathrm{KCl}, 1.25$ $\mathrm{NaH}_{2} \mathrm{PO}_{4}$, and $0.5 \mathrm{CaCl}_{2}, 7 \mathrm{MgSO}_{4}, 25 \mathrm{D}$-glucose, 11.6 sodium ascorbate, 3.1 sodium pyruvate). Coronal slices ( $300 \mu \mathrm{m}$ thick) of the right cerebral hemisphere containing the motor cortex were cut at a slice angle pitched forward $\sim 10^{\circ}$ off the coronal plane to align the slice plane optimally with the radial axis of the cortex (i.e., parallel to pyramidal neuron apical dendrites and descending axons). Slices were transferred to and incubated in carbogenated artificial CSF (ACSF) (in mm: $126 \mathrm{NaCl}, 2.5 \mathrm{KCl}$, $26 \mathrm{NaHCO}_{3}, 2 \mathrm{CaCl}_{2}, 1 \mathrm{MgCl}_{2}, 1.25 \mathrm{NaH}_{2} \mathrm{PO}_{4}$, and 10 D-glucose) for 30 min at $35^{\circ} \mathrm{C}$, and then maintained at $21^{\circ} \mathrm{C}$ until recording.

Electrophysiology and glutamate uncaging photostimulation. Whole-cell recordings of excitatory or inhibitory inputs in voltage-clamp mode were performed as described previously (Wood et al., 2009; Anderson et al., 2010; Wood and Shepherd, 2010). Excitatory inputs were recorded at $-70 \mathrm{mV}$ (the calculated reversal potential for GABAergic inhibitory conductances) with either K-based intracellular solution (in mм: 128 K-methylsulfonate, $4 \mathrm{MgCl}_{2}$, 10 HEPES, 1 EGTA, 4 ATP, 0.3 GTP, $10 \mathrm{~mm}$ phosphocreatine, Alexa 594, and either 0 or $0.3-0.5 \%$ biocytin) or Cs-based intracellular solution (in mM: same, but with 128 Csmethanesulfonate). Inhibitory inputs were recorded at $\sim 0 \mathrm{mV}$ with Csbased intracellular solution. Glutamate uncaging and laser-scanning photostimulation (LSPS) maps were performed as described previously (Weiler et al., 2008; Shepherd, 2011) at $21^{\circ} \mathrm{C}$ in modified ACSF solution [4 $\mathrm{mM} \mathrm{CaCl}_{2}, 4 \mathrm{mM} \mathrm{MgCl}_{2}, 5 \mu \mathrm{M}$ 3-[(R)-2-carboxypiperazin-4yl]propyl-1-phosphonate (CPP) to block NMDA receptor-mediated currents, $0.2 \mathrm{~mm}$ MNI-caged glutamate; drugs from Tocris]. Intrinsic properties were recorded with $\mathrm{K}$-based intracellular solution at $34^{\circ} \mathrm{C}$. Signals were filtered at $4 \mathrm{kHz}$ and sampled at $10 \mathrm{kHz}$. The software program Ephus (Suter et al., 2010) (www.ephus.org) was used for hardware control and data acquisition.

A subset of the recorded neurons were filled with biocytin and stained for light-microscopic morphological identification and reconstruction. Neurons were morphologically reconstructed in three dimensions using Neurolucida (MicroBrightField) and an upright microscope fitted with a $100 \times / 0.9$ oil-immersion objective.

In utero electroporation. DNA plasmids encoding a fusion protein of channelrhodopsin-2 (ChR2) and Venus driven by the CAG promoter (pCAGGS-ChR2-Venus; Addgene plasmid 15753) (Petreanu et al., 2007) were transfected into layer $2 / 3$ neurons of the mouse motor cortex by in utero electroporation as described previously (Wood et al., 2009). Pregnant mice were deeply anesthetized by inhaled isoflurane, and a laparotomy was performed to externalize the uterus. The right lateral ventricle of embryonic day 16.5 embryos were injected with a solution containing $\sim 1$ $\mu \mathrm{l}$ of $1 \mu \mathrm{g} \mu \mathrm{l}^{-1}$ ChR2-Venus plasmids and Fast Green (Sigma-Aldrich; included to help visualize the intraventricular injection) via a glass pipette sharpened with a beveller (Narishige). Electroporation was performed with five pulses, each at $50 \mathrm{~V}$ for $50 \mathrm{~ms}$, with a $1 \mathrm{~s}$ interpulse interval.

ChR2-assisted circuit mapping. In brain slices from in utero-transfected mice, ChR2-assisted circuit mapping (CRACM) (Petreanu et al., 2007) was used to map inputs from transfected layer $2 / 3$ pyramidal neurons and their axons, as described previously (Anderson et al., 2010). Excitatory and inhibitory CRACM maps were recorded using Cs-based intracellular solution (at $34^{\circ} \mathrm{C}$ in standard ACSF containing $5 \mu \mathrm{M} \mathrm{CPP}$ ). Because of variability both in transfection efficiency (number of ChR2expressing neurons per animal) and ChR2 expression levels (number of ChR2 molecules per transfected neuron), we empirically determined a suitable laser power for each slice, and used this for all cells recorded subsequently in the same slice. Specifically, we first patched a corticospinal neuron in layer $5 \mathrm{~B}$, adjusted the laser power to give inputs of $\sim 100$-pA peak amplitude following stimulation at perisomatic sites, and then obtained CRACM maps at this power level. Next, we patched a corticostriatal neuron in the same slice located in either layer $5 \mathrm{~A}$ or $5 \mathrm{~B}$ and acquired excitatory and inhibitory CRACM maps at the same power.

Retrograde delivery of ChR2 via rabies virus. Recombinant deletionmutant rabies virus encoding ChR2 (RV-ChR2) was generated as described previously (Wickersham et al., 2010; Kiritani et al., 2012) (see also Osakada et al., 2011). Deletion-mutant RV, as noted previously (Wickersham et al., 2007), is ideal for retrograde transfection because of its tropism for axons, absence of transsynaptic spread (due to deletion of the glycoprotein gene), high transgene expression levels, and low cytotoxicity. Injections of RV-ChR2 $\left(1.3 \times 10^{9}\right.$ infectious units per $\left.\mathrm{ml}\right)$ were made with an oil hydraulic manipulator (Narishige MO-10) and Drummond Wiretrol capillary pipettes, targeting either the dorsolateral striatum $(0.2$ $\mu \mathrm{l})$ or cervical spinal cord $(1.2-1.5 \mu \mathrm{l})$ using the same coordinates and conditions used for the injection of the fluorescent microspheres. Anatomical retrograde labeling with inert tracers was performed in the same animals by injecting fluorescent microspheres (Retrobeads; Lumafluor) into the contralateral striatum and spinal cord, as described above. Brain slice experiments were performed $4-8 \mathrm{~d}$ later.

Data analysis. Group data represent the mean \pm SEM. Group comparisons were made using Student's $t$ test if data were normally distributed (assessed with Lilliefors' test) and the rank sum test if not, with significance defined as $p<0.05$.

\section{Results}

This study consists of three interrelated sets of experiments. First, we surveyed across all layers for local sources of excitatory inputs to interneurons. Second, we analyzed descending (interlaminar: layer $2 / 3 \rightarrow 5 \mathrm{~A} / \mathrm{B}$ ) excitation to interneurons and its role in descending disynaptic inhibition to projection neurons. Third, we analyzed lateral (intralaminar: layer $5 \mathrm{~A} / \mathrm{B} \rightarrow 5 \mathrm{~A} / \mathrm{B}$ ) excitation to 

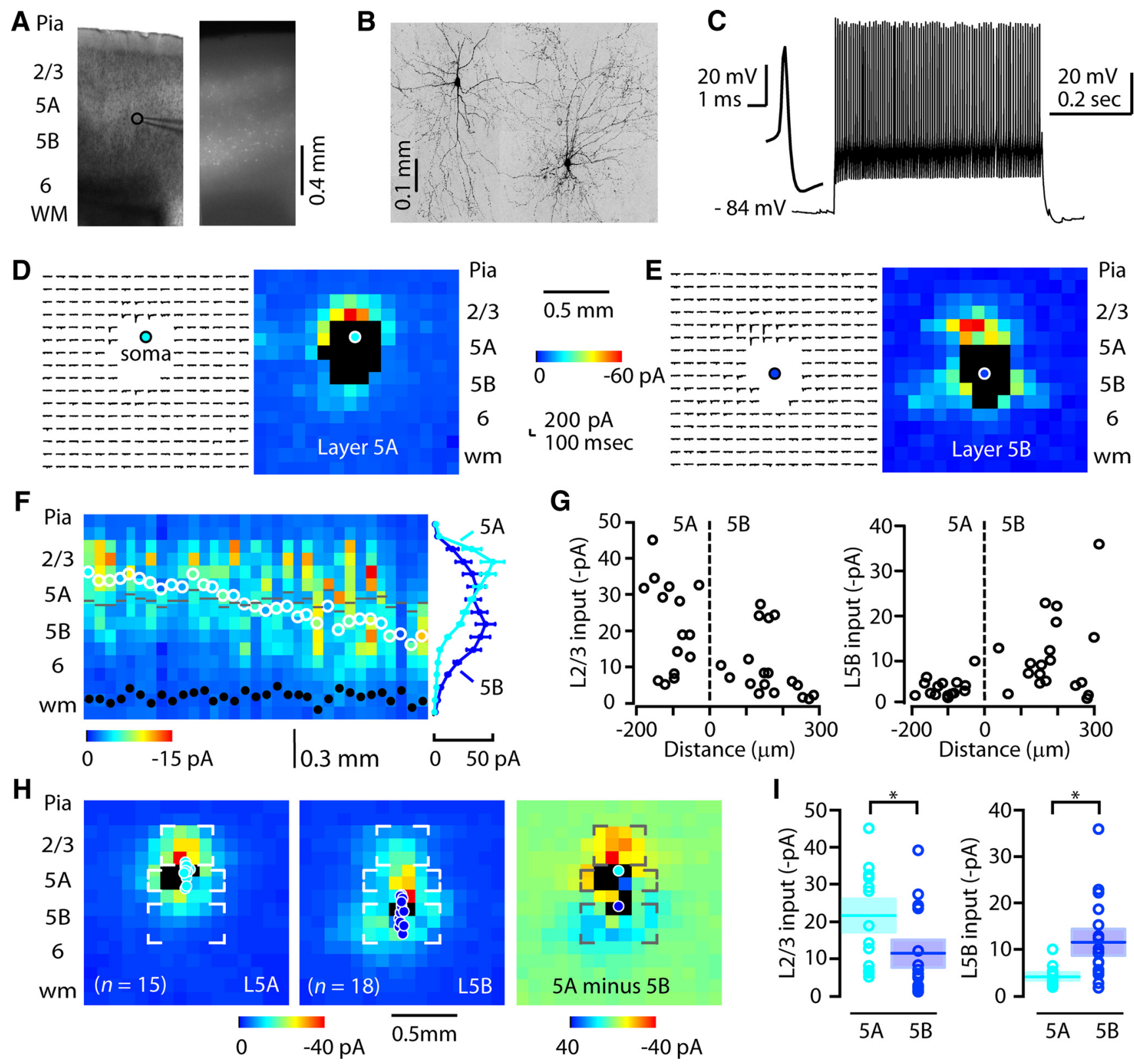

Figure 1. Excitatory inputs to FS interneurons. $A$, Bright-field (BF) (left) and epifluorescence (right) images of a $\mathrm{G} 42$ transgenic mouse line motor cortex slice. $\boldsymbol{B}$, High-resolution image of biocytin-labeled FS interneurons. $\boldsymbol{C}$, Train of action potentials recorded in a GFP-positive cell during step current injection ( $0.5 \mathrm{~s}, 200 \mathrm{pA}$ pulse). Inset, Single action potential. $\boldsymbol{D}$, Example of excitatory input traces and map recorded from a layer 5 A FS interneuron. $\boldsymbol{E}$, Same, for a layer $5 B$ FS interneuron. $\boldsymbol{F}$, Side-view projection of FS interneuron input maps $(n=33)$, ordered by soma distance from the layer $5 \mathrm{~A} / \mathrm{B}$ border. Maps were projected onto one plane by averaging along the rows of the individual maps. Different symbols mark the absolute distances from the pia to the soma (white circles), the layer $5 \mathrm{~A} / 5 \mathrm{~B}$ border (gray dashes), and layer $6 /$ white matter (WM) border (black circles). Plots on the right show the average amount of input to layer $5 \mathrm{~A}$ (lighter blue) and layer $5 \mathrm{~B}$ (darker blue) FS interneurons (mean \pm SEM). G, Average excitatory input from layer $2 / 3$ (left) and $5 B$ (right) as a function of soma location relative to the layer $5 \mathrm{~A} / 5 \mathrm{~B}$ border (pia is leftward and white matter is rightward). $\boldsymbol{H}$, Average maps of $\mathrm{FS}$ interneurons in layers $5 \mathrm{~A}(n=15$; left $)$ and $5 \mathrm{~B}(n=18$; middle), and difference map (right), generated by subtracting the $5 \mathrm{~B}$ map from the $5 \mathrm{~A}$ map. The brackets indicate regions of interest (ROls). $I$, Mean amplitude of layer $2 / 3$ (left) and layer $5 B$ (right) excitatory input to layer $5 \mathrm{~A}$ and $5 B$ FS interneurons, for the R0ls bracketed in the maps. ${ }^{*} p<0.01$.

interneurons and its role in lateral disynaptic inhibition both to and from projection neurons.

\section{Excitatory inputs to FS interneurons in layers 5A and 5B}

We studied the local excitatory inputs onto FS interneurons in layers $5 \mathrm{~A}$ and $5 \mathrm{~B}$ of the mouse primary motor cortex (Fig. 1). In mouse neocortex, "layer 5 " consists of (at least) two distinct layers, layers 5A and 5B (Caviness, 1975; Schubert et al., 2006; Yu et al., 2008; Anderson et al., 2010). Previous studies (Kaneko et al., 2000; Weiler et al., 2008; Anderson et al., 2010) have shown that pyramidal neurons in layers $5 \mathrm{~A}$ and $5 \mathrm{~B}$ in motor cortex receive excitatory input from layer $2 / 3$ pyramidal neurons. These inputs, however, vary as a function of the axonal projection target and precise sublaminar location of the neuron. In consideration of this, our goal was to determine whether the local circuits of FS interneurons in layers 5A and 5B also followed cell type- and layer-specific rules.

We prepared brain slices containing the motor cortex from the G42 transgenic mouse line, in which GFP is expressed in a subset of FS interneurons (Chattopadhyaya et al., 2004). This allowed us to identify and record from these FS-type interneurons in layers $5 \mathrm{~A}$ and $5 \mathrm{~B}$ (Fig. $1 \mathrm{~A}$ ). We verified their identity 
based on characteristic basket cell-type morphology (Fig. 1B) and electrophysiology, including fast (narrow) spikes and highfrequency firing during prolonged current steps (Fig. 1C). In a subset of experiments, we recorded (in normal ACSF at $34^{\circ} \mathrm{C}$ ) from FS interneurons $(n=9)$ to characterize basic electrophysiological properties, including the following: resting membrane potential, $-74.5 \pm 1.9 \mathrm{mV}$; action potential threshold, $-43.0 \pm$ $1.6 \mathrm{mV}$; rheobase, $288 \pm 32 \mathrm{pA}$; action potential width, $0.31 \pm$ $0.02 \mathrm{~ms}$; frequency-current $(f-I)$ relationship slope, $0.56 \pm 0.07$ $\mathrm{Hz} / \mathrm{pA}$; sag amplitude, $17.3 \pm 2.9 \mathrm{mV}$.

We used glutamate uncaging and LSPS to map local excitatory inputs in these brain slices of motor cortex (in high-divalent ACSF with NMDA blockers, at $21^{\circ} \mathrm{C}$ ) (see Materials and Methods). Advantages and disadvantages of this technique have been discussed extensively (Shepherd et al., 2003; Weiler et al., 2008; Shepherd, 2011). Here, we emphasize the utility of this tool as an initial screen, or survey, because it provides relatively high spatial resolution, well suited for mapping laminar pathways, and it excites presynaptic neurons indiscriminately; that is, without particular selectivity for different subtypes of pyramidal neurons (contrasting, for example, with optogenetic methods explicitly designed for such selectivity, as described later). Interneurons were recorded at $-70 \mathrm{mV}$ to measure EPSCs evoked by photostimulation of presynaptic neurons. FS interneurons in layers $5 \mathrm{~A}$ and $5 \mathrm{~B}$ received excitatory inputs from local sources distributed over multiple layers around the neurons (Fig. $1 D, E$ ). For the mapping conditions used here, we have previously established that excitatory responses represent compound (as opposed to unitary) monosynaptic (as opposed to disynaptic/polysynaptic) inputs arising from clusters of presynaptic excitatory neurons activated at the site of the laser flash, and that the resolution of LSPS for mapping excitatory inputs is $\sim 50-100 \mu \mathrm{m}$ (average distance of photostimulated pyramidal neurons from the center of the laser beam) (Weiler et al., 2008; Wood and Shepherd, 2010; Hooks et al., 2011). These synaptic input maps thus represent the spatial distribution of presynaptically connected neurons around the recorded neuron.

A limitation of these maps is that they lack information about a region around the soma (black pixels in maps), which could not be probed for synaptic inputs due to the contamination of responses by direct glutamatergic stimulation of dendrites of the recorded neuron. This was quantified by calculating the area of this somatodendritic footprint (blind spot) and also of the synaptic input footprint (region over which inputs were detected) (Lam and Sherman, 2011). The somatodendritic footprint was similar for FS interneurons in layers $5 \mathrm{~A}$ and $5 \mathrm{~B}(5 \mathrm{~A}, 0.140 \pm$ $0.088 \mathrm{~mm}^{2}, n=15 ; 5 \mathrm{~B}, 0.165 \pm 0.012 \mathrm{~mm}^{2}, n=18 ; p=0.10, t$ test) as was the synaptic footprint $\left(5 \mathrm{~A}, 1.83 \pm 0.09 \mathrm{~mm}^{2} ; 5 \mathrm{~B}\right.$, $1.88 \pm 0.06 \mathrm{~mm}^{2} ; p=0.4$, rank sum test). The ratios of the synaptic to somatodendritic footprints were high $(5 \mathrm{~A}, 0.91 ; 5 \mathrm{~B}$, 0.92 ) (i.e., $<10 \%$ of the synaptic area was excluded from the maps by the somatodendritic blind spot). However, the excluded region undoubtedly includes sites of strong inputs; thus, the amount of intralaminar input represents a lower bound. Later in the study, we return to this issue and use optogenetic strategies to overcome this limitation.

Input maps showed considerable neuron-to-neuron variability in input topography and strength. Some neurons received many and strong inputs, while others received sparse and weak inputs. The locations of the inputs were generally close to the soma in layers $5 \mathrm{~A}$ or $5 \mathrm{~B}$ and/or from sites in layer $2 / 3$; most inputs came from within several hundred micrometers laterally or vertically. However, when the maps were ordered based on the lam- inar soma position of the interneurons, and projected onto a single plane by averaging along map rows, a pattern emerged (Fig. $1 F$ ). Inputs from layer $2 / 3$ were variable but overall tended to decrease with soma depth, whereas inputs from layer $5 \mathrm{~B}$ tended to increase with soma depth (Fig. $1 F, G$ ). The transition from strong to weak layer $2 / 3$ input did not coincide precisely with the border between layers $5 \mathrm{~A}$ and $5 \mathrm{~B}$ (in contrast to excitatory inputs to corticostriatal and corticospinal neurons) (see below) (Anderson et al., 2010) but appeared graded, with the transition from a layer 2/3-predominant to layer 5B-predominant pattern culminating with FS interneurons more than $\sim 200 \mu \mathrm{m}$ below the layer 5A/B border (Fig. $1 F, G$ ). As noted above, some neurons received relatively few inputs and did not clearly adhere to the overall patterns.

To characterize further the topographic organization of the excitatory input onto FS interneurons in layers $5 \mathrm{~A}$ and $5 \mathrm{~B}$, we generated average maps for these two groups. On average, FS interneurons in layer $5 \mathrm{~A}(n=15)$, compared with those in $5 \mathrm{~B}$ $(n=18)$, received more excitatory input from layer $2 / 3(5 \mathrm{~A}$ neurons, $-21 \pm 3.3 \mathrm{pA}$; $5 \mathrm{~B}$ neurons, $-11.5 \pm 2.6 \mathrm{pA} ; p=0.006$, rank sum test) and less excitatory input from layer $5 \mathrm{~B}(5 \mathrm{~A}$, $-4.2 \pm 0.4 \mathrm{pA} ; 5 \mathrm{~B},-11.6 \pm 2.0 \mathrm{pA} ; p=0.002, t$ test), but comparable amounts of layer 5A excitatory input $(5 \mathrm{~A},-14.4 \pm$ $1.3 \mathrm{pA} ; 5 \mathrm{~B},-19.6 \pm 3.1 \mathrm{pA} ; p=0.66$, rank sum test) (Fig. $1 H, I)$. We recognize that layer-based averaging in this manner is somewhat arbitrary, since changes occurred gradually across layers; nevertheless, this approach is useful for quantifying trends and for comparison to results presented later where the laminar effects were stronger. These data suggest that the local excitatory input to FS interneurons in layers $5 \mathrm{~A}$ and $5 \mathrm{~B}$ depends on soma location, with the deeper FS interneurons receiving less layer $2 / 3$ input and more layer $5 \mathrm{~B}$ input.

\section{Excitatory inputs to LTS interneurons in layers 5A and 5B}

To determine whether another class of inhibitory interneurons, LTS interneurons, follows similar excitatory circuit organization, we used the GIN transgenic mouse line, in which GFP is expressed in a subset of LTS interneurons (Oliva et al., 2000; Halabisky et al., 2006; Ma et al., 2006). This allowed us to record from labeled LTS interneurons in layers $5 \mathrm{~A}$ and $5 \mathrm{~B}$ in motor cortex slices (Fig. 2A). Consistent with earlier work (Amitai et al., 2002), LTS interneurons morphologically resembled Martinotti-type interneurons (seven of seven biocytin-filled neurons) (Fig. $2 B$ ). Basic electrophysiological properties (recorded in normal ACSF at $\left.34^{\circ} \mathrm{C}\right)$ for LTS interneurons $(n=11)$ included the following (Fig. $2 \mathrm{~B}$ ): resting membrane potential, $-67.6 \pm 1.9 \mathrm{mV}$; action potential threshold, $-48.9 \pm 1.3 \mathrm{mV}$; rheobase, $64 \pm 8 \mathrm{pA}$; action potential width, $0.59 \pm 0.04 \mathrm{~ms} ; f-I$ slope, $0.34 \pm 0.02 \mathrm{~Hz} / \mathrm{pA}$ step; sag amplitude, $16.0 \pm 3.2 \mathrm{mV}$.

Synaptic input maps for individual LTS interneurons in both layers $5 \mathrm{~A}$ and $5 \mathrm{~B}$ showed variability, often with strong excitatory inputs from layer $2 / 3$, and notably weaker and/or sparse input from layers $5 \mathrm{~A}$ and $5 \mathrm{~B}$ (Fig. $2 \mathrm{D}, \mathrm{E}$ ). The size of the somatodendritic footprint was slightly (24\%) larger for LTS interneurons in 5A compared with $5 \mathrm{~B}\left(5 \mathrm{~A}, 0.214 \pm 0.009 \mathrm{~mm}^{2}, n=17 ; 5 \mathrm{~B}, 0.172 \pm 0.012 \mathrm{~mm}^{2}\right.$, $n=14 ; p=0.01, t$ test $)$; in contrast, the synaptic footprint, as well as the ratio of the synaptic to somatodendritic footprints, was bigger $(22 \%)$ for LTS interneurons in 5B compared with 5A (5A, $0.84 \pm$ $0.03 \mathrm{~mm}^{2} ; 5 \mathrm{~B}, 1.08 \pm 0.04 \mathrm{~mm}^{2} ; p=1 \times 10^{-4}, t$ test; ratio $5 \mathrm{~A}, 0.79$; ratio $5 \mathrm{~B}, 0.86)$. Ordering the maps by soma position and rowaveraging the map data to project them onto a single plane showed that, although many neurons received input from layer $2 / 3$, the total amount of layer $2 / 3$ input was variable but gradually declined as a 

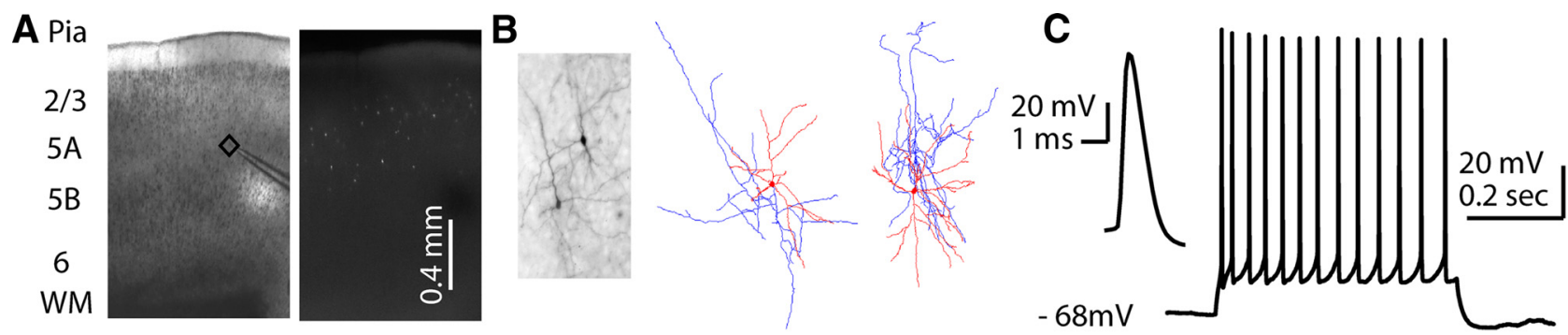

\section{D}
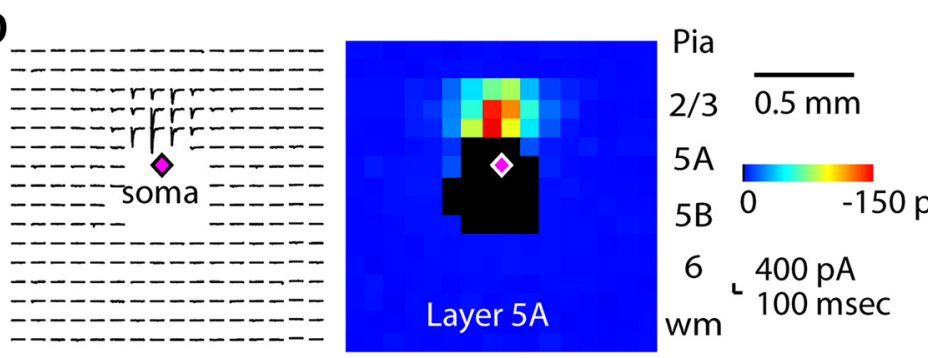

$\mathrm{E}$
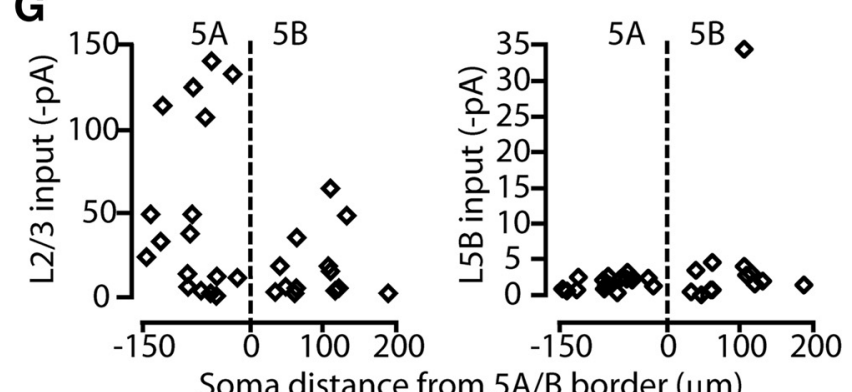
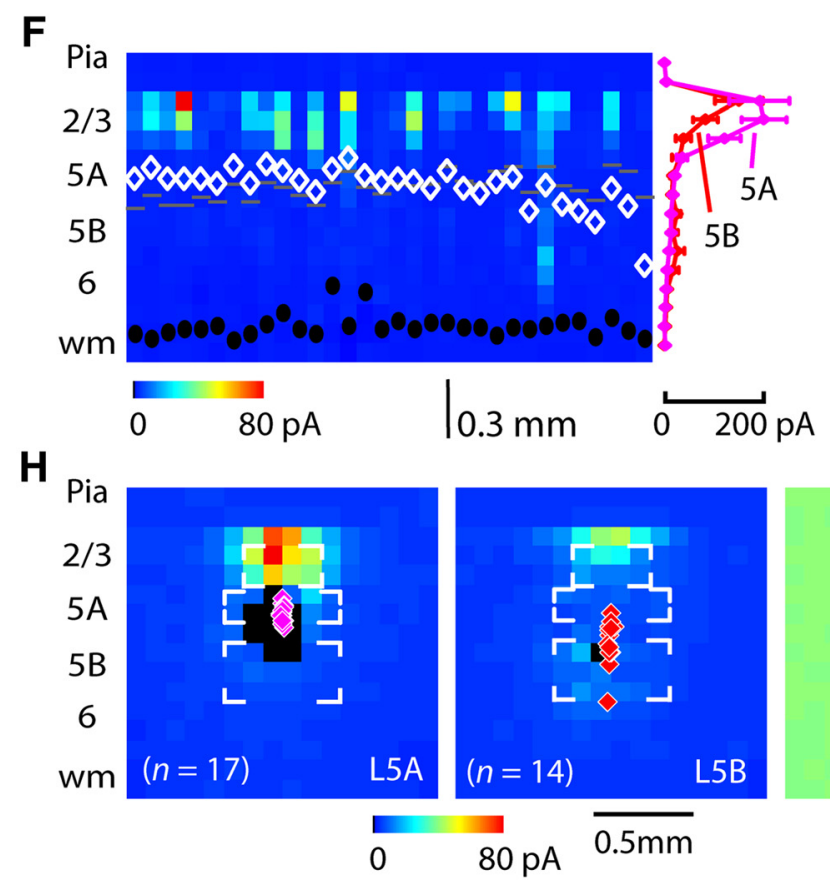

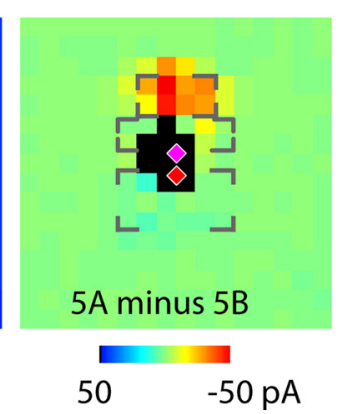

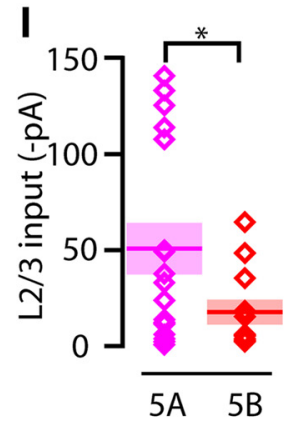

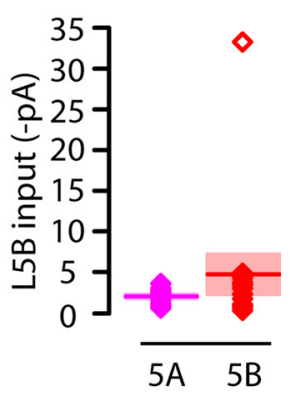

Figure 2. Excitatory inputs to LTS interneurons. A, Bright-field (BF) (left) and epifluorescence (right) images of a GIN transgenic mouse line motor cortex slice. B, Left, Bright-field image of biocytin-stained

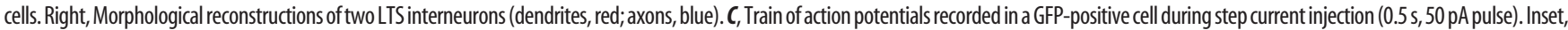
Single action potential. $\boldsymbol{D}$, Example of excitatory input traces and map recorded from a layer 5 A LTS interneuron. $\boldsymbol{E}$, Example of excitatory input traces and map recorded from a layer $5 B$ LTS interneuron. $\boldsymbol{F}$, Side-view projection of LTS input maps $(n=31)$. Symbols are as defined in Figure $1 F$. G, Average excitatory input from layer $2 / 3$ (left) and $5 B$ (right) as a function of soma location relative to the layer $5 A / 5 B$ border. $\boldsymbol{H}$, Average maps of LTS interneurons in layer $5 \mathrm{~A}$ (left; $n=17$ ) and $5 \mathrm{~B}$ (middle; $n=14$ ), and difference map (right; $5 \mathrm{~B}$ map minus $5 \mathrm{~A}$ map). The brackets indicate ROls. Note that here the layer $2 / 3$ ROI is centered on the lower part of layer 2/3.I, Mean amplitude of layer $2 / 3$ (left) and layer $5 B$ (right) excitatory input to layer $5 A$ and $5 B$ LTS interneurons, for the ROls bracketed in the maps. ${ }^{*} p<0.05$.

function of increasing soma depth; in contrast, inputs from layer $5 \mathrm{~B}$ were generally weak and independent of soma position (Fig. $2 F, G$ ). Layer-averaged maps showed that LTS interneurons in layer 5A received more excitatory input from lower layer $2 / 3$ than those in layer $5 \mathrm{~B}$ (5A neurons, $-50.8 \pm 12.3 \mathrm{pA}, n=17 ; 5 \mathrm{~B}$ neurons, $-17.1 \pm 5.6$ pA, $n=14 ; p=0.04, t$ test; Fig. $2 H, I)$. Moreover, LTS interneurons in both layers $5 \mathrm{~A}$ and $5 \mathrm{~B}$ received similar excitatory input from upper layer $2 / 3(5 \mathrm{~A},-55.0 \pm 17.2 \mathrm{pA} ;-39.7 \pm 13.3 \mathrm{pA} ; p=0.62$, rank sum test) and generally weak excitatory input from layers $5 \mathrm{~A}$ and $5 \mathrm{~B}$. These data suggest that the local excitatory circuit organization of LTS interneurons in both layers $5 \mathrm{~A}$ and $5 \mathrm{~B}$ depends on soma location, with layer 5A LTS interneurons receiving more input especially from lower layer $2 / 3$. Because these patterns appear to differ from those observed for FS interneurons, in the next section we compare FS and LTS results in greater detail.

Comparison of excitatory input to FS and LTS interneurons

We further analyzed these data sets to make direct comparisons of the excitatory input topography for FS and LTS interneurons. In layer 5A, calculating a difference image showed that by far the greatest difference between FS and LTS interneurons was that LTS interneurons received much stronger (by a factor of $\sim 3$ ) excitatory input from layer $2 / 3$ (FS, $-19.0 \pm 3.3 \mathrm{pA}, n=15$; LTS, $-55.0 \pm 14.4$ pA, $n=17 ; p=0.05$, $t$ test; Fig. $3 A, B)$. Layer 5A FS interneurons, however, received stronger layer $5 \mathrm{~B}$ excitatory input compared with layer 5A LTS interneurons (FS, $-4.2 \pm 0.4$ 


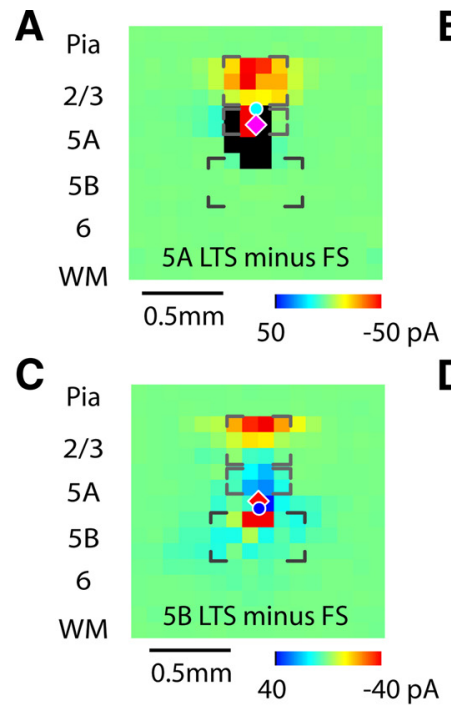

E
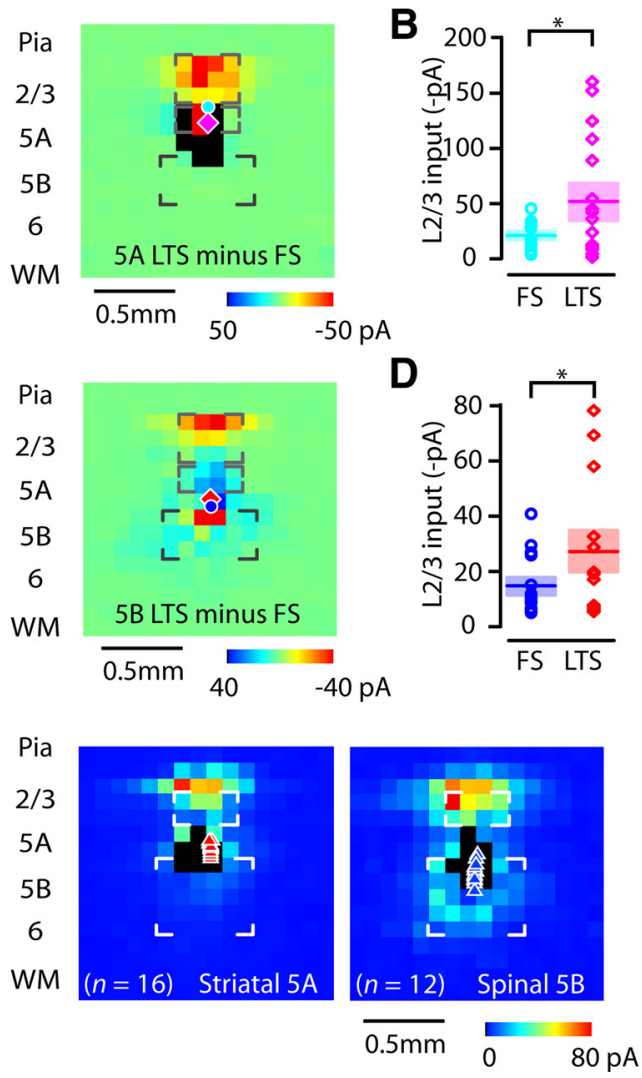
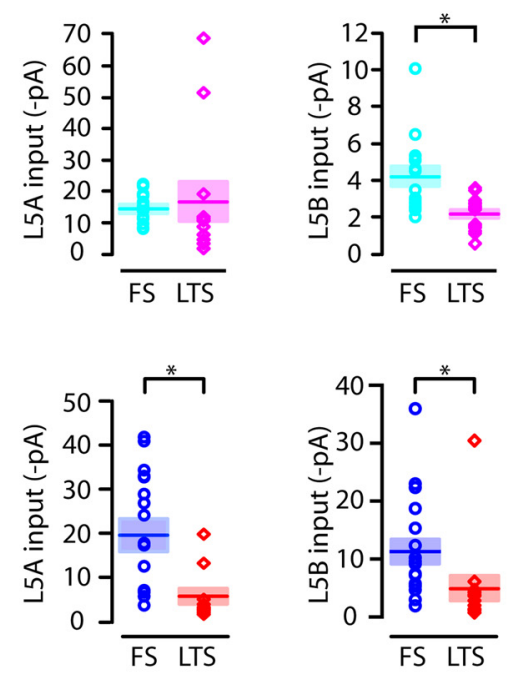

$\mathbf{F}$

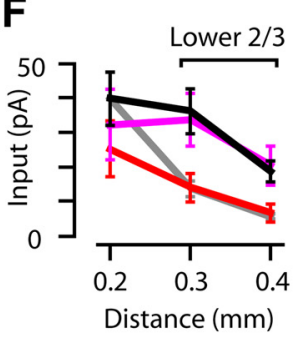

G

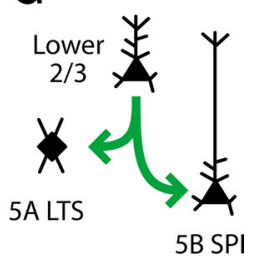

Figure 3. Comparison of FS and LTS interneurons, and of excitatory inputs to inhibitory and excitatory neurons in layers $5 \mathrm{~A}$ and $5 \mathrm{~B}$. $A$, Difference map, calculated by subtracting the average map for layer $5 \mathrm{~A} \mathrm{FS}(n=15)$ from that of LTS $(n=17)$ interneurons. $\boldsymbol{B}, \mathrm{ROI}$-averaged excitatory input from layers $2 / 3$ (for an R0I spanning all of layer $2 / 3$ ), $5 \mathrm{~A}$, and $5 \mathrm{~B}$ to FS and LTS interneurons in layer $5 A$. ROls are marked by brackets in the maps. ${ }^{*} p \leq 0.05$. C, Difference map, calculated by subtracting the average map for layer $5 B$ FS $(n=18)$ from that of LTS $(n=14)$ interneurons. $D$, ROl-averaged excitatory input from layers $2 / 3,5 \mathrm{~A}$, and $5 \mathrm{~B}$ to FS and LTS interneurons in layer 5B. ROls are marked by brackets in the maps. ${ }^{*} p<0.05 . E$, Average maps of layer $5 \mathrm{~A}$ corticostriatal ( $n=$ 16) and layer $5 B$ corticospinal $(n=12)$ neurons. ROls are marked by brackets in the maps. The layer $2 / 3$ ROI was centered onto the lower layer $2 / 3$ as indicated by the brackets. $F$, Average excitatory inputs ( \pm SEM) to layer 5 A corticostriatal neurons (red), layer 5 A LTS interneurons (black), layer $5 B$ corticospinal neurons (blue), and layer $5 B$ LTS interneurons (gray) as a function of distance of the stimulus location (i.e., location of presynaptic neurons) from the pia. $\mathbf{G}$, Schematic depicting the laminar pattern of excitatory output from lower layer $2 / 3$ to LTS interneurons in layer $5 \mathrm{~A}$ and corticospinal neurons in layer 5B.

pA; LTS, $-2.2 \pm 0.2 \mathrm{pA} ; p=3 \times 10^{-4}, t$ test; Fig. $\left.3 B\right)$. Layer $5 \mathrm{~A}$ excitatory input did not differ (FS, $-14.4 \pm 1.3 \mathrm{pA}$; LTS, $-16.7 \pm 6.1 \mathrm{pA} ; p=0.15$, rank sum test). The average somatodendritic footprint of 5A FS interneurons was smaller than that of 5A LTS interneurons (FS, $0.140 \pm 0.088 \mathrm{~mm}^{2}$; LTS, $0.214 \pm$ $0.009 \mathrm{~mm}^{2} ; p=3 \times 10^{-6}, t$ test $)$ possibly contributing to the greater amount of layer $5 \mathrm{~B}$ excitatory input observed for FS interneurons. Later in this study, we present experiments that circumvent the footprint-related limitations. The considerations associated with the somatodendritic footprints did not pertain to the main difference in input maps.

In layer $5 \mathrm{~B}$, a difference image showed again that by far the largest difference was that LTS interneurons, compared with FS interneurons, received much more (by a factor of $\sim 3$ ) excitatory input from layer $2 / 3$ (FS, $-9.8 \pm 2.1 \mathrm{pA}, n=18$; LTS, $-27.3 \pm$ $8.7 \mathrm{pA}, n=14 ; p=0.03, t$ test $)$. In addition, they received less from both layer $5 \mathrm{~A}(\mathrm{FS},-19.6 \pm 3.1 \mathrm{pA}$; LTS, $-5.72 \pm 1.9 \mathrm{pA}$; $p=9 \times 10^{-4}$, rank sum test) and from layer $5 \mathrm{~B}$ (FS, $-11.6 \pm 2.0$ pA; LTS, $-4.7 \pm 2.1 \mathrm{pA} ; p=6 \times 10^{-4}$, rank sum test) (Fig. $3 C, D)$. In this case, the intralaminar differences were not associated with different average footprints between FS and LTS interneurons in layer $5 \mathrm{~B}$ (FS, $0.165 \pm 0.017 \mathrm{~mm}^{2}$; LTS, $0.172 \pm$ $0.012 \mathrm{~mm}^{2} ; p=0.67, t$ test $)$.

As expected, the intrinsic properties of FS and LTS interneurons also differed. Three intrinsic properties of the FS interneu- rons in layers $5 \mathrm{~A}$ and $5 \mathrm{~B}(n=9)$ tend to make them less excitable compared with LTS interneurons $(n=11)$ : resting membrane potentials were $\sim 7 \mathrm{mV}$ more hyperpolarized ( $p=0.03, t$ test); action potential thresholds were $\sim 6 \mathrm{mV}$ higher $(p=0.03, t$ test); and rheobases were $\sim 200$ pA higher (FS, $288.9 \pm 31.8$ pA; LTS, $63.6 \pm 7.8 \mathrm{pA} ; p=1 \times 10^{-4}$ rank sum test). Above threshold, FS interneurons fired briskly, with steeper $f-I$ slopes than LTS interneurons ( $p=0.01, t$ test).

Overall, these data show that FS and LTS interneurons in layers 5A and 5B have distinct laminar excitatory circuit organization in motor cortex. LTS interneurons tend to receive more input from layer $2 / 3$, and less input from layers $5 \mathrm{~A}$ and $5 \mathrm{~B}$, compared with FS interneurons.

\section{Comparison of excitatory input to LTS interneurons versus corticostriatal and corticospinal neurons}

Because the pattern of strong layer $2 / 3$ excitatory input to LTS interneurons resembles that reported for deeper-layer pyramidal neurons (Weiler et al., 2008; Anderson et al., 2010; Sheets et al., 2011), we compared the excitatory input organization of the layer $5 \mathrm{~A}$ corticostriatal neurons and layer $5 \mathrm{~B}$ corticospinal neurons to layers $5 \mathrm{~A}$ and $5 \mathrm{~B}$ LTS interneurons. For this, we retrogradely labeled both "crossed" corticostriatal neurons and corticospinal neurons (by injecting fluorescent beads into the dorsolateral striatum and into the cervical spinal cord, respectively) (see Ma- 

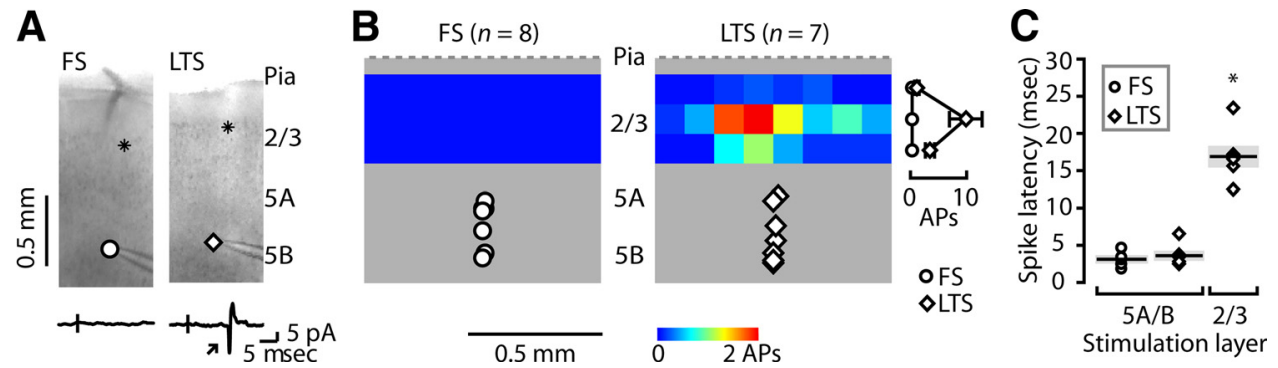

Figure 4. Interlaminar versus intralaminar driving of FS and LTS interneurons. $A$, Left, Bright-field images of motor cortex slices prepared from the G42 (left) or the GIN (right) mouse line, showing the locations of the recording interneurons (FS, circle; LTS, diamond), layer 2/3 stimulation sites (asterisks), and examples of responses recorded in cell-attached mode; the LTS but not the FS interneuron fired an action potential (arrow). $\boldsymbol{B}$, Average excitation profiles for FS (left; $n=8$ ) and LTS (right; $n=7$ ) interneurons. Grid spacing, $100 \mu \mathrm{m}$. Plots on the right show the average number of action potentials to layer $5 \mathrm{~A} / 5 \mathrm{~B} F \mathrm{~F}$ (circles) and layer $5 \mathrm{~A} / 5 \mathrm{~B}$ LTS (diamonds) interneurons (mean \pm SEM). C, Latency to first action potential in response to glutamate uncaging, recorded in FS and LTS interneurons, for layer 5A/B (left) and layer 2/3 (right) photostimulation locations (symbols: individual data points for each cell; bars: group means \pm SEM).
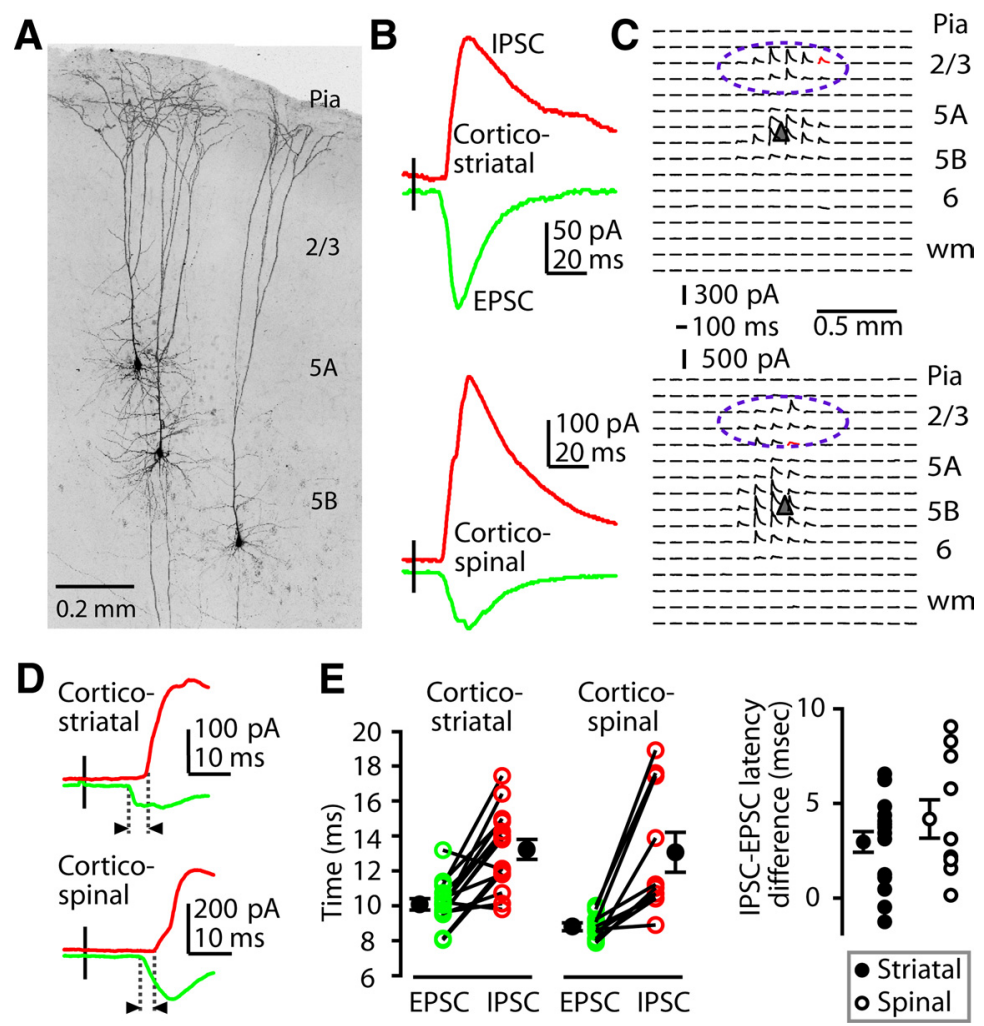

Figure 5. Latency of the layer $2 / 3$ inhibitory inputs to corticostriatal and corticospinal neurons. $A$, Example image showing several biocytin-labeled corticospinal neurons in layer $5 B$ of motor cortex. B, Examples of EPSCs (green trace) recorded at $-70 \mathrm{mV}$ and IPSCS (red trace) recorded at $0 \mathrm{mV}$ from a layer 5B corticostriatal (top) and corticospinal (bottom) neurons. C, Example of inhibitory input traces recorded from layer $5 B$ corticostriatal (top) and corticospinal (bottom) neurons. Dashed ellipse, Region in layer $2 / 3$ where IPSCs were evoked. D, Example traces showing latency differences between onset of IPSCs (red trace) versus EPSCs (green trace) for corticostriatal (top) and corticospinal (bottom) neurons. E, Onset latencies recorded in corticostriatal ( $n=15$; left) and corticospinal ( $n=10$; right) neurons, for EPSCS (green circles) and IPSCs (red circles). The filled circles show group averages ( \pm SEM). Right, Plot of IPSC-EPSC latency differences calculated for individual IPSC-EPSC pairs, for corticostriatal and corticospinal neurons, including group averages ( \pm SEM).

terials and Methods) and mapped their local excitatory inputs. As shown previously (Anderson et al., 2010), upper layer 5B corticospinal neurons received stronger excitatory input from lower layer $2 / 3$ compared with layer $5 \mathrm{~A}$ corticostriatal neurons $(5 \mathrm{~B}$ corticospinal, $-49.8 \pm 9.4 \mathrm{pA}, n=12$; 5 A corticostriatal, $-19.3 \pm$ $2.9 \mathrm{pA}, n=16 ; p=0.02$, rank sum test); both projection types received similar amounts of excitatory input from upper layer $2 / 3$ (5B corticospinal, $-63.4 \pm 11.7 \mathrm{pA} ; 5 \mathrm{~A}$ corticostriatal, $-62.6 \pm$ $12.6 \mathrm{pA} ; p=0.97, t$ test; Fig. $3 E$ ). Moreover, layer $5 \mathrm{~B}$ corticospinal neurons received stronger excitatory input from layer 5B com- pared with layer $5 \mathrm{~A}$ corticostriatal $(5 \mathrm{~B}$ corticospinal, $-13.9 \pm 2.1 \mathrm{pA} ; 5 \mathrm{~A}$ corticostriatal, $-3.6 \pm 0.5 \mathrm{pA} ; p=7 \times 10^{-6}, t$ test), but not significantly different excitatory input from layer $5 \mathrm{~A}$ ( $5 \mathrm{~B}$ corticospinal, $-10.2 \pm 1.2 \mathrm{pA} ; 5 \mathrm{~A}$ corticostriatal, $-8.7 \pm 1.2 \mathrm{pA} ; p=0.37$, rank sum test).

Unexpectedly, input maps of LTS interneurons in layer $5 \mathrm{~B}$ resembled those of corticostriatal neurons in layer $5 \mathrm{~A}$, receiving excitatory input preferentially from upper layer $2 / 3$, and conversely, input maps of LTS interneurons in layer $5 \mathrm{~A}$ resembled those of corticospinal neurons in layer $5 \mathrm{~B}$, receiving excitatory input from all of layer $2 / 3$ (Fig. $3 E, F$ ). In the latter comparison, the similarities pertained to the inputs from layer $2 / 3$ but not those from deeper layers; layer 5A LTS interneurons received less excitatory input from layer $5 \mathrm{~B}$ compared with upper layer $5 \mathrm{~B}$ corticospinal neurons (5B corticospinal, $-13.9 \pm 2.1 \mathrm{pA}, n=12$; 5 A LTS, $-2.1 \pm 0.2 \mathrm{pA}, n=17 ; p=2 \times 10^{-7}, t$ test). These data indicate that the axons of lower layer $2 / 3$ pyramidal neurons selectively innervate excitatory projection neurons in one layer (5B corticospinal neurons) and inhibitory interneurons in an adjacent layer (LTS in layer 5A) (Fig. 3G).

\section{Descending pathways: interlaminar driving of LTS interneurons}

The finding of strong synaptic excitation from layer $2 / 3$ pyramidal neurons to LTS interneurons in layers $5 \mathrm{~A}$ and $5 \mathrm{~B}$ suggested the possibility of synaptic driving in this excitatory-toinhibitory pathway. To assess this, we performed cell-attached recordings from FS and LTS interneurons and mapped the spatial distribution of sites where action potentials were evoked by glutamate uncaging (Fig. 4A,B). We found differences between the two classes of interneurons in where and when action potentials were evoked. Both FS and LTS interneurons fired action potentials following perisomatic stimulation (in layers $5 \mathrm{~A}$ or $5 \mathrm{~B}$ ), with no significant spike latency difference (FS, $2.9 \pm 0.2 \mathrm{~ms}, n=8$; 
LTS, $3.4 \pm 0.5 \mathrm{~ms}, n=7$; $p=0.34$, $t$ test; Fig. $4 C$ ), but in contrast, LTS but not FS interneurons fired action potentials following stimulation in layer $2 / 3$, with longer spike latencies compared with the perisomatic latencies (LTS, layer $2 / 3$ stimulation, $16.6 \pm 1.2 \mathrm{~ms}$; FS, 5A/B stimulation, $2.9 \pm 0.2 \mathrm{~ms} ; p=3 \times 10^{-4}$, rank sum test; LTS, 5A/B stimulation, $3.4 \pm 0.5$ $\mathrm{ms} ; p=6 \times 10^{-4}$, rank sum test; Fig. $4 C$ ). These data indicate that layer $2 / 3$ pyramidal neurons can synaptically drive action potentials in LTS but not FS interneurons in layers $5 \mathrm{~A}$ and $5 \mathrm{~B}$.

\section{Inhibitory inputs to corticostriatal and} corticospinal neurons

If LTS interneurons in layers 5A and 5B, in addition to being synaptically driven by layer 2/3 excitation (as shown above; Fig. 4), also send their own inhibitory output to projection neurons, then maps of inhibitory input to projection neurons should include layer $2 / 3$ sites that represent a disynaptic inhibitory pathway (i.e., layer $2 / 3$ pyramidal neurons $\rightarrow$ LTS interneurons $\rightarrow$ projection neurons). To test this prediction, we recorded from retrogradely labeled projection neurons (Fig. $5 A$ ) and isolated uncaging-evoked EPSCs and IPSCs by applying a command potential of either $-70 \mathrm{mV}$ (the calculated reversal potential for GABAergic inhibitory conductances) or $0 \mathrm{mV}$ (the calculated reversal potential for glutamatergic excitatory conductances) (Fig. 5B). Example input maps showed that both corticostriatal and corticospinal neurons received inhibitory input evoked by stimulation sites located in multiple layers, including layer $2 / 3$ (Fig. $5 C$ ).

To evaluate the possibility of layer $2 / 3$ disynaptic inhibition onto corticostriatal and corticospinal neurons, we analyzed the timing of the excitatory and inhibitory input (Fig. 5D). For layer $2 / 3$ stimulation sites, the onset of IPSCs lagged that of EPSCs with a short delay for both corticostriatal and corticospinal neurons (corticostriatal, $3.1 \pm 0.6 \mathrm{~ms}, n=15$; corticospinal, $4.2 \pm 1 \mathrm{~ms}, n=$ $10 ; p=0.3, t$ test) (Fig. $5 E$ ). This latency difference is consistent with the recruitment of IPSCs through a disynaptic mechanism by layer $2 / 3$ axons.

\section{Layer 2/3 disynaptic inhibition to corticostriatal and corticospinal neurons}

Because glutamate uncaging activates both excitatory and inhibitory neurons, the foregoing analysis did not rigorously exclude the possibility that inhibitory inputs to projection neurons arose through other mechanisms; for example, monosynaptic input from direct activation of layer $2 / 3$ interneurons, rather than from disynaptic inhibition. To resolve this, we used an optogenetic approach to activate selectively only excitatory neurons, providing a direct and unambiguous assay for disynaptic inhibition (Hull et al., 2009; Adesnik and Scanziani, 2010; Cruikshank et al., 2010). We performed in utero electroporation on E16.5 embryos to deliver the light-activated cation channel ChR2 to a sparse population of layer $2 / 3$ pyramidal neurons (Fig. $6 A$ ). In voltageclamp mode, under more physiological recording conditions (ACSF: $2 \mathrm{~mm} \mathrm{CaCl}_{2}, 1 \mathrm{~mm} \mathrm{MgCl}_{2}, 5 \mu \mathrm{M} \mathrm{CPP}$ at $34^{\circ} \mathrm{C}$ ), EPSCs and IPSCs were recorded in corticostriatal and corticospinal neurons during mapping (Fig. 6A, $B$ ). The only ChR2-expressing neurons were layer $2 / 3$ pyramidal neurons, including their axons, which remained photoexcitable even when severed from their parent somata (Petreanu et al., 2007). Thus, these results establish the presence of layer $2 / 3$ disynaptic interlaminar inhibition impinging on these two projectionally defined classes of pyramidal neurons in layers $5 \mathrm{~A}$ and $5 \mathrm{~B}$ of motor cortex. The total amounts of excitatory and disynaptic inhibitory inputs per neuron were strongly correlated ( $R^{2}=0.87 ; n=12$ neurons). As expected, the latencies of EPSCs and IPSCs were shorter under these more physiological recording conditions (compared with those obtained with glu-LSPS), as were (accordingly) the IPSC-EPSC latency differences, which were similar for the two projection classes (corticostriatal, $1.1 \pm 0.4 \mathrm{~ms}, n=5$; corticospinal, $1.3 \pm$ $0.3 \mathrm{~ms}, n=5$; $p=0.6, t$ test) (Fig. 6C). These data indicate that IPSCs in corticostriatal and corticospinal neurons can be triggered in a disynaptic manner by layer $2 / 3$ pyramidal neurons.

Lateral pathways: intralaminar excitation of FS interneurons by corticostriatal and corticospinal neurons

In this last section of the study, we return to the question of the intralaminar sources of excitation to FS and LTS interneurons. As 
A

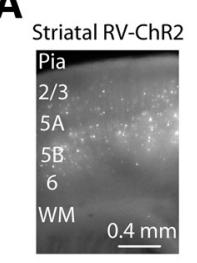

E

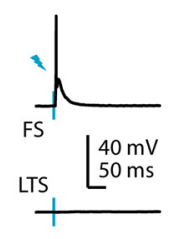

B
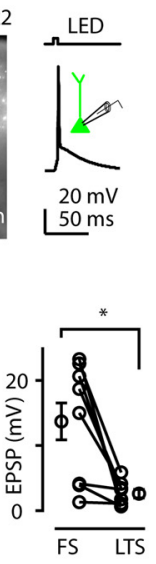

F
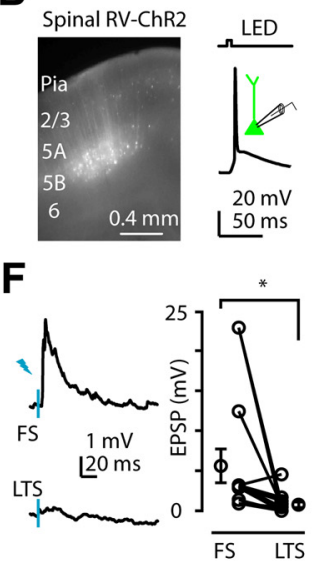

C

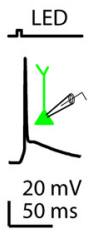

$20 \mathrm{mV}$

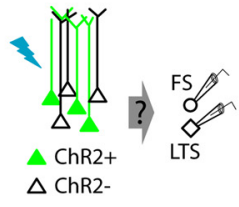

G Presynaptic:

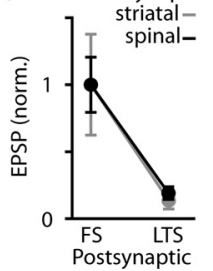

D

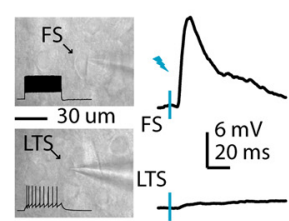

H

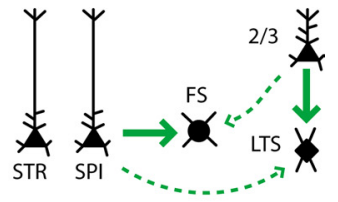

Figure 7. RV-ChR2 photostimulation-evoked excitation from corticospinal or corticostriatal neurons to FS and LTS cells. A, Epifluorescence image of a mouse motor cortex slice showing retrogradely labeled corticostriatal neurons following injection of RV-ChR2 into contralateral striatum. Right, Photostimulation-evoked action potential recorded from ChR2 + corticostriatal neuron, in response to $5 \mathrm{~ms}$ pulse of light from a blue LED (top trace). $\boldsymbol{B}$, Same as in $\boldsymbol{A}$, but for corticospinal neurons. Corticospinal neurons were retrogradely transfected by injection of RV-ChR2 into spinal cord. $\boldsymbol{C}$, Experimental paradigm for photostimulating ChR2 + projection neurons while recording responses in FS and LTS interneurons. These experiments were performed in the GIN mouse line. D, Examples showing morphology and firing patterns of FS (top left) and LTS (bottom left) interneurons, as seen in bright-field microscopy during patch recordings, and EPSPs recorded in layer $5 B$ FS (top right) and LTS interneurons (bottom right) during ChR2-corticostriatal photostimulation. $\boldsymbol{E}$, Example showing an action potential recorded in an FS (top left) but not an LTS (bottom left) interneuron during ChR2-corticostriatal photostimulation. Right, Plot of photoevoked corticostriatal output to pairs of layer $5 B F S$ and LTS interneurons. Pairs are connected by lines; group averages ( $\pm S E M$ ) are plotted to either side. ${ }^{*} p=0.005 . F, S a m e$ as in $E$, for $C h R 2$-corticospinal photostimulation. ${ }^{*} p<0.01$. G, Normalized version of the group data in $\boldsymbol{E}$ and $\boldsymbol{F}$. $\boldsymbol{H}$, Schematic depicting major excitatory pathways to $\mathrm{FS}$ and LTS interneurons.

noted earlier, glutamate uncaging is unable to probe perisomatic sites to detect the most proximally located presynaptic neurons. In addition, glutamate uncaging does not allow for selective activation of different classes of projection neurons. To address these issues, and also to explore the possible roles of FS and LTS interneurons in mediating inhibition between corticostriatal and corticospinal neurons, we used an optogenetic strategy. We selectively expressed ChR2 in either corticostriatal or corticospinal neurons via retrograde transfection with a recombinant rabies virus (RV) encoding ChR2 (Fig. 7 A,B). The expression of ChR2 throughout the infected neurons enabled selective photo-control of action potentials in these projection neurons and their axons. Recordings from transfected corticostriatal or corticospinal neurons established that brief $(5 \mathrm{~ms})$ pulses of blue light $(470 \mathrm{~nm})$ reliably elicited short-latency action potentials (Fig. $7 A, B$ ).

We performed RV-ChR2 transfection of corticostriatal or corticospinal neurons in the GIN mouse line (Fig. 7C) and recorded from (sequential) pairs of (unlabeled) FS and (GFPpositive) LTS interneurons in motor cortex slices (Fig. 7D). Photostimulation of ChR2-expressing corticostriatal neurons elicited EPSPs in layer 5B FS interneurons that were much stronger (by a factor of $\sim 5$ ) than in LTS interneurons (FS, $13.7 \pm 3.2$ $\mathrm{mV}, n=10$; LTS, $2.5 \pm 0.7 \mathrm{mV}, n=10 ; p=0.005$, $t$ test) (Fig. $7 D, E)$. In some of the FS ( 3 of 10 cells) but not in the LTS ( 0 of 10 cells) interneurons, synaptic inputs were strong enough to generate action potentials (Fig. 7E). Similarly, photoevoked corticospinal output to interneurons was highly asymmetric, nearly an order of magnitude stronger to FS than to LTS interneurons (FS, $5.6 \pm 1.9 \mathrm{mV}$; LTS, $0.6 \pm 0.3 \mathrm{mV} ; p=0.008$, rank sum test) (Fig. $7 F, G$ ). These results show that layer 5B FS interneurons receive the most intralaminar excitation from projection neurons (Fig. $7 \mathrm{H}$ ).

\section{FS-mediated disynaptic inhibition between corticostriatal and corticospinal neurons}

We used the same RV-ChR2 strategy to examine intralaminar disynaptic inhibition between corticostriatal and corticospinal neurons (Fig. $8 A$ ). We recorded EPSCs and IPSCs from (sequen- tial) pairs of untransfected corticostriatal and corticospinal neurons (i.e., ChR2-negative, but retrogradely labeled) in the same slice. Photoactivation of either corticostriatal or corticospinal neurons demonstrated disynaptic inhibitory inputs to both classes of projection neuron (Fig. $8 \mathrm{~B}$ ). These ChR2-evoked disynaptic IPSCs were abolished in the presence of the glutamate receptor antagonists NBQX (10 $\mu \mathrm{M}$, to block AMPA-mediated responses) and CPP ( $5 \mu \mathrm{M}$, to block NMDA-mediated responses; $n=3$ corticostriatal and 2 corticospinal neurons), confirming they were elicited by synaptic transmission (Fig. $8 B$ ).

As reported previously [for EPSPs (Kiritani et al., 2012)], corticostriatal photostimulation consistently generated excitatory responses in both corticostriatal and corticospinal neurons, with similar amplitudes (corticostriatal, $-256 \pm 55 \mathrm{pA}, n=10$; corticospinal, $-354 \pm 53 \mathrm{pA}, n=7 ; p=0.09$, paired $t$ test) (Fig. $8 C$ ). In the same postsynaptic neurons, corticostriatal photostimulation also consistently evoked disynaptic inhibitory responses in both projection classes, but in this case average amplitudes were larger (by a factor of $\sim 2$ ) in the corticospinal neurons (corticostriatal, $679 \pm 143 \mathrm{pA}, n=10$; corticospinal, $1518 \pm 263 \mathrm{pA}, n=$ $7 ; p=0.003$, paired $t$ test) (Fig. $8 C$ ).

We repeated this analysis to assess the output from corticospinal neurons to these two classes of projection neurons. Untransfected corticostriatal and corticospinal neurons both received inhibitory inputs (Fig. $8 D, E$ ). However, in this case, as reported previously [for EPSPs (Kiritani et al., 2012)], corticospinal excitatory output was highly asymmetric, projecting much more strongly to corticospinal than to corticostriatal neurons; although the sample size was small (for larger data sets, see Kiritani et al., 2012), one of the corticostriatal neurons received no detectable input and two others received only weak input. Disynaptic inhibition from corticospinal neurons, in contrast, was consistently detected in both corticospinal and corticostriatal neurons; although a trend toward more disynaptic inhibition to corticospinal neurons was seen (similar to that observed for corticostriatal-evoked disynaptic inhibition, as described above), this did not reach statistical significance (corticostriatal, $206 \pm 65$ $\mathrm{pA}, n=4$; corticospinal, $449 \pm 155 \mathrm{pA}, n=3 ; p=0.12$, paired $t$ test). However, because of the asymmetry of excitation, cortico- 
A

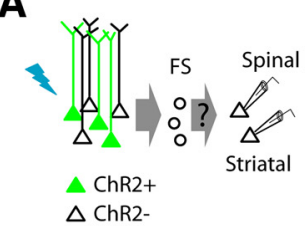

B

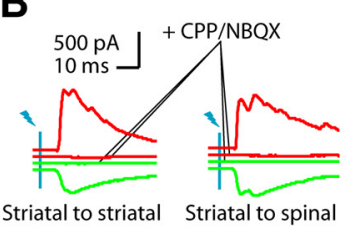

C

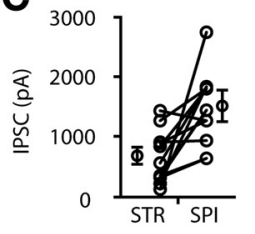

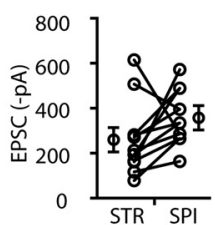

D

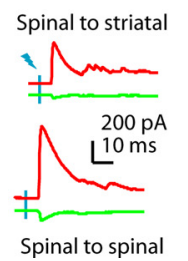

E

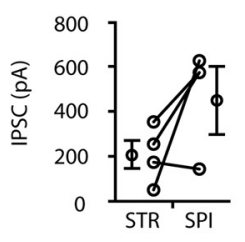

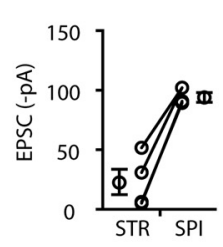

F

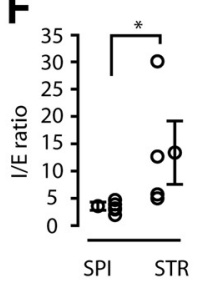

G

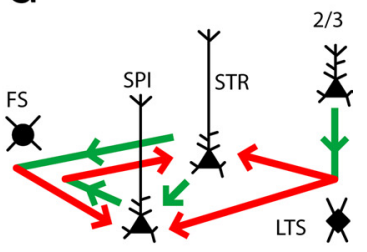

Figure 8. RV-ChR2 photostimulation-evoked disynaptic inhibition between corticospinal and corticostriatal neurons. $A$, Experimental paradigm for stimulating ChR2 + projection neurons while recording from untransfected (ChR2 -) neurons identified as corticostriatal or corticospinal by anatomical retrograde labeling (bead +), to evaluate disynaptic inhibition. B, ChR2-corticostriatal photostimulation evoked a small EPSC (green traces) and large IPSC (red traces) in bead-labeled corticostriatal (left) and corticospinal (right) neurons. The excitatory and inhibitory currents were abolished by application of ionotropic glutamate receptor antagonists (5 $\mu \mathrm{M}$ CPP, $10 \mu \mathrm{M}$ NBQX). C, Amplitudes of IPSPs (left) and EPSPs (right) recorded in corticospinal and corticostriatal neurons while photostimulating ChR2-expressing corticostriatal neurons. D, EPSPs (green traces) and IPSCS (red traces) recorded in a layer $5 \mathrm{~B}$ corticostriatal neuron during ChR2-corticospinal photostimulation (top), and in a layer 5B corticospinal neuron during ChR2-corticospinal photostimulation (bottom). E, Amplitudes of IPSPs (left) and EPSPs (right) recorded in corticospinal and corticostriatal neurons while photostimulating ChR2-expressing corticospinal neurons. F, IPCS/EPSC ratio of photoevoked corticostriatal output to layer $5 B$ corticospinal $(n=6)$, and IPCS/EPSC ratio of photoevoked corticospinal output to layer $5 B$ corticostriatal $(n=4)$ neurons. Group averages ( \pm SEM) are plotted to either side. ${ }^{*} p<0.05$. G, Schematic depicting disynaptic inhibitory pathways between pyramidal neurons.

striatal neurons received a relatively strong net inhibitory influence from corticospinal neurons (Fig. $8 F$ ). Overall, these results, together with those for the descending pathways reported earlier in this study, delineate a complex microcircuit involving multiple cell type- and layer-specific disynaptic inhibitory pathways between pyramidal neurons (Fig. 8G).

\section{Discussion}

In this study of inhibitory microcircuits in mouse motor cortex, we first mapped the local sources of excitatory synaptic input to FS and LTS interneurons in layers $5 \mathrm{~A}$ and $5 \mathrm{~B}$, and then evaluated the roles of these two classes of interneurons in mediating disynaptic inhibition to two classes of pyramidal (projection) neurons, corticostriatal and corticospinal neurons. We found that FS and LTS interneurons in layers $5 \mathrm{~A}$ and $5 \mathrm{~B}$ were recruited differentially by interlaminar (layer $2 / 3 \rightarrow 5 \mathrm{~A} / \mathrm{B}$ ) versus intralaminar (layer $5 \mathrm{~A} / \mathrm{B} \rightarrow$ layer $5 \mathrm{~A} / \mathrm{B}$ ) input. Specifically, pyramidal neurons in layer $2 / 3$ synaptically excited LTS interneurons (Fig. $3 G$ ), implicating these interneurons as potential contributors in mediating disynaptic inhibition from layer $2 / 3$ pyramidal neurons to corticostriatal and corticospinal neurons (Fig. 8G). In contrast, corticostriatal and corticospinal neurons synaptically excited FS interneurons (Fig. 7H), implicating these interneurons in mediating disynaptic inhibition within and across the two classes of projection neurons (Fig. 8G).

We have addressed a number of technical considerations throughout the presentation of the methods and results; here, we summarize some of the key issues. First, we emphasize the advantages of the combined use of glu-LSPS and ChR2photostimulation for mapping microcircuits. The merits and shortcoming of both photostimulation-based tools (uncaging vs optogenetic) were highly complementary; for example, the nonselectivity of glutamate uncaging permitted a broad imaging-based survey of local connections with relatively high spatial resolution, whereas ChR2 activation allowed cell types of interest to be activated selectively. A particularly useful aspect of ChR2 photostimulation was that it enabled rapid and direct measurement of disynaptic inhibitory responses (Hull et al., 2009; Adesnik and Scanziani, 2010; Cruikshank et al., 2010), and we expect this, particularly in combi- nation with retrograde labeling and RV-mediated transfection, to be a useful tool for further studies of inhibitory microcircuits of cortical projection neurons. Second, we underscore that both photostimulation methods provided information at the level of synaptic projections, not unitary connections. Specifically, these methods revealed the aggregate output from the activated neurons, reflecting both probabilities and amplitudes of the underlying unitary connections. Our findings therefore do not exclude the possibility of an additional level of fine-scale specificity in the connections among small groups of individual neurons (Yoshimura and Callaway, 2005). From a systems perspective, the projection level, manifesting both the probabilities and amplitudes of the underlying unitary connectivity, may be particularly relevant for understanding the overall flow of activity in cortical circuits (Freeman, 1975; Weiler et al., 2008; Lefort et al., 2009; Neymotin et al., 2011).

One of two main findings was that FS interneurons in layers 5A and 5B (compared with LTS interneurons) are excited powerfully by corticostriatal and corticospinal neurons, but weakly by layer $2 / 3$ pyramidal neurons. This finding is consistent with previous results demonstrating high probabilities for intralaminar connections from pyramidal neurons to FS interneurons (Thomson et al., 2002; Beierlein et al., 2003; Holmgren et al., 2003; Oswald et al., 2009; Otsuka and Kawaguchi, 2009; Xu and Callaway, 2009; Tanaka et al., 2011; Avermann et al., 2012), although it contrasts with results from rat visual cortex showing predominantly interlaminar excitation of FS interneurons in layer $2 / 3$ (Dantzker and Callaway, 2000). Our results extend those previous observations by showing that two distinct types of projection neurons (corticostriatal and corticospinal) are both sources of excitatory output to FS interneurons.

The second main finding was that LTS interneurons in layers $5 \mathrm{~A}$ and $5 \mathrm{~B}$ have the opposite (compared with FS interneurons) pattern of microcircuit connectivity with the three types of presynaptic pyramidal neurons studied here: they are strongly excited by layer $2 / 3$ pyramidal neurons, and weakly excited by corticostriatal and corticospinal neurons. Our findings are largely consistent with previous results demonstrating connec- 
tions from layer $2 / 3$ pyramidal neurons to LTS-type interneurons in layer 5 (Kapfer et al., 2007), including a higher probability of unitary connections from layer $2 / 3$ pyramidal neurons to non-FS interneurons compared with FS interneurons (Otsuka and Kawaguchi, 2009). However, in rat prefrontal cortex, the excitatory connectivity from layer $2 / 3$ to layer 5 interneurons depends (for both FS and non-FS interneurons) on presynaptic but not postsynaptic laminar location (Otsuka and Kawaguchi, 2009). Here, an unexpected topographic pattern emerged from comparison of layer 2/3 excitation to LTS interneurons and corticospinal neurons, showing a dependence on both presynaptic and postsynaptic laminar location (Fig. $3 G$ ). Further experiments are needed to understand the functional significance of this topographic organization, but it invites speculation that the excitatory output from lower layer $2 / 3$ could enhance the activity of interneurons in one layer (e.g., layer 5A LTS interneurons) and thereby potentially inhibit (via disynaptic inhibition) the activity of excitatory neurons such as corticostriatal neurons in that layer, while enhancing the activity of projection neurons in another layer (e.g., layer 5B corticospinal neurons). Considered in the context of motor control mechanisms, this arrangement could in principle provide a way to shift activity from circuits mediating motor planning (involving corticocortical and corticostriatal neurons) to circuits mediating motor execution (involving corticospinal and corticobulbar neurons). Such a shift could be reinforced by the asymmetric excitatory connectivity in the corticostriatal-corticospinal microcircuit, resulting in weak excitation but strong disynaptic inhibition in the corticospinal-tocorticostriatal direction (Fig. $8 F, G$ ).

In addition to mapping the excitatory output from different types of pyramidal neurons to FS and LTS interneurons, we also examined disynaptic inhibitory pathways (i.e., from excitatory neurons via inhibitory interneurons to excitatory neurons). Corticostriatal and corticospinal neurons received strong disynaptic inhibition from every presynaptic source tested (layer $2 / 3$ pyramidal, corticostriatal, and corticospinal neurons). However, several results provided circumstantial evidence that at least some fraction of the interlaminar disynaptic inhibition from layer $2 / 3$ may be mediated by LTS interneurons in layers $5 \mathrm{~A}$ and $5 \mathrm{~B}$, while intralaminar disynaptic inhibition from the deeper-layer projection neurons may be mediated primarily by FS interneurons in those layers. Further work is needed to assess the extent to which LTS, FS, and other classes of interneurons mediate intralaminar and interlaminar disynaptic inhibitory signaling under different states of motor cortex activity in vivo.

In motor cortex recordings in vivo, multiple cell types in deeper layers, including neurons with fast spikes assumed to be interneurons, show movement-related activity (Beloozerova et al., 2003a,b; Merchant et al., 2008; Isomura et al., 2009; Kaufman et al., 2010) (but see Vigneswaran et al., 2011). Recently, it has been shown by anatomical methods that FS-type interneurons provide the strongest source of local inhibition to corticospinal neurons (Tanaka et al., 2011). Indeed, intralaminar FS-to-pyramidal projections have been observed in multiple cortical areas as a major local source of intralaminar inhibition (Thomson and Lamy, 2007; Brill and Huguenard, 2009; Kätzel et al., 2011). We found that the strongest excitatory drive to FS interneurons was from the two classes of projection neurons in layers 5A and 5B. Thus, these two projections (corticostriatal/ corticospinal to FS, and FS to corticostriatal/corticospinal) appear to be chained together, forming a strong intralaminar disynaptic inhibitory pathway among corticostriatal/corticospinal neurons. The disynaptic inhibition between projection neurons was not projection specific but was instead similar for within-class and bidirectionally across-class projections; these pathways thus evidently provide a substrate for omnidirectional inhibitory cross talk between corticostriatal and corticospinal neurons. In terms of the hierarchical organization of the excitatory network (Kiritani et al., 2012), because corticostriatal-to-corticospinal is a feedforward excitatory pathway, these omnidirectional pathways can be considered to represent feedforward (corticostriatal-to-corticospinal), feedback (corticospinalto-corticostriatal), and recurrent (within-class, for corticostriatal and corticospinal) disynaptic inhibitory pathways. Our findings do not exclude the possibility of connection-specific dynamics in these microcircuits (Kiritani et al., 2012); indeed, in rat motor cortex, facilitating and depressing connections onto FS interneurons have been shown to arise from layer 5 pyramidal neurons with more or less complex dendritic morphology, respectively (Angulo et al., 2003).

The interlaminar disynaptic inhibitory pathway from layer $2 / 3$ was also projection nonspecific, being comparable for corticostriatal and corticospinal neurons. The preferential targeting of LTS (and avoidance of FS) interneurons in this pathway is interesting to consider in light of evidence that excitatory output from layer $2 / 3$ to layer 5 exerts a net activating influence on layer 5 pyramidal neurons, in contrast to a net suppressing influence for intralaminar connections (Adesnik and Scanziani, 2010). In paired recordings of layer 5 pyramidal neurons, LTS-type rather than FS-type interneurons have primarily been observed to mediate disynaptic inhibition (Kapfer et al., 2007; Silberberg and Markram, 2007; Berger et al., 2009, 2010; Zhu et al., 2011). LTSmediated disynaptic inhibition is highly frequency dependent, emerging with a delay during trains of action potentials in the presynaptic pyramidal neurons. Here, we focused our analysis on synaptic responses evoked by single stimuli rather than trains, and did not explore frequency-dependent phenomena. The ubiquity of the LTS-mediated disynaptic microcircuit (Berger et al., 2009) suggests it would be engaged in motor cortex during highfrequency activity associated with motor behavior (Murthy and Fetz, 1992). Consistent with this possibility, increased LTS activity is associated with active exploration in somatosensory cortex (Gentet et al., 2010). Our findings provide a structural basis for functional analysis of dynamic signaling in the inhibitory/projection neuron microcircuits identified here and how they contribute to the control of purposive movements.

\section{References}

Adesnik H, Scanziani M (2010) Lateral competition for cortical space by layer-specific horizontal circuits. Nature 464:1155-1160.

Amitai Y, Gibson JR, Beierlein M, Patrick SL, Ho AM, Connors BW, Golomb D (2002) The spatial dimensions of electrically coupled networks of interneurons in the neocortex. J Neurosci 22:4142-4152.

Anderson CT, Sheets PL, Kiritani T, Shepherd GMG (2010) Sublayerspecific microcircuits of corticospinal and corticostriatal neurons in motor cortex. Nat Neurosci 13:739-744.

Angulo MC, Staiger JF, Rossier J, Audinat E (2003) Distinct local circuits between neocortical pyramidal cells and fast-spiking interneurons in young adult rats. J Neurophysiol 89:943-953.

Avermann M, Tomm C, Mateo C, Gerstner W, Petersen CC (2012) Microcircuits of excitatory and inhibitory neurons in layer $2 / 3$ of mouse barrel cortex. J Neurophysiol. Advance online publication. Retrieved March 7, 2012. doi:10.1152/jn.00917.2011.

Beierlein M, Gibson JR, Connors BW (2003) Two dynamically distinct inhibitory networks in layer 4 of the neocortex. J Neurophysiol 90:2987-3000.

Beloozerova IN, Sirota MG, Swadlow HA (2003a) Activity of different classes of neurons of the motor cortex during locomotion. J Neurosci 23:1087-1097.

Beloozerova IN, Sirota MG, Swadlow HA, Orlovsky GN, Popova LB, Delia- 
gina TG (2003b) Activity of different classes of neurons of the motor cortex during postural corrections. J Neurosci 23:7844-7853.

Berger TK, Perin R, Silberberg G, Markram H (2009) Frequency-dependent disynaptic inhibition in the pyramidal network: a ubiquitous pathway in the developing rat neocortex. J Physiol 587:5411-5425.

Berger TK, Silberberg G, Perin R, Markram H (2010) Brief bursts selfinhibit and correlate the pyramidal network. PLoS Biol 8:pii:e1000473.

Brill J, Huguenard JR (2009) Robust short-latency perisomatic inhibition onto neocortical pyramidal cells detected by laser-scanning photostimulation. J Neurosci 29:7413-7423.

Brown SP, Hestrin S (2009) Cell-type identity: a key to unlocking the function of neocortical circuits. Curr Opin Neurobiol 19:415-421.

Caviness VS Jr (1975) Architectonic map of neocortex of the normal mouse. J Comp Neurol 164:247-263.

Chattopadhyaya B, Di Cristo G, Higashiyama H, Knott GW, Kuhlman SJ, Welker E, Huang ZJ (2004) Experience and activity-dependent maturation of perisomatic GABAergic innervation in primary visual cortex during a postnatal critical period. J Neurosci 24:9598-9611.

Cruikshank SJ, Urabe H, Nurmikko AV, Connors BW (2010) Pathwayspecific feedforward circuits between thalamus and neocortex revealed by selective optical stimulation of axons. Neuron 65:230-245.

Dantzker JL, Callaway EM (2000) Laminar sources of synaptic input to cortical inhibitory interneurons and pyramidal neurons. Nat Neurosci 3:701-707.

DeFelipe J (1997) Types of neurons, synaptic connections and chemical characteristics of cells immunoreactive for calbindin-D28K, parvalbumin and calretinin in the neocortex. J Chem Neuroanat 14:1-19.

Fino E, Yuste R (2011) Dense inhibitory connectivity in neocortex. Neuron 69:1188-1203.

Fishell G, Rudy B (2011) Mechanisms of inhibition within the telencephalon: "where the wild things are." Annu Rev Neurosci 34:535-567.

Freeman WJ (1975) Mass action in the nervous system. New York: Academic.

Gentet LJ, Avermann M, Matyas F, Staiger JF, Petersen CC (2010) Membrane potential dynamics of GABAergic neurons in the barrel cortex of behaving mice. Neuron 65:422-435.

Georgopoulos AP, Stefanis CN (2010) The motor cortical circuit. In: Handbook of brain microcircuits (Shepherd GM, Grillner S, eds), pp 39-45. New York: Oxford UP.

Gonchar Y, Wang Q, Burkhalter A (2007) Multiple distinct subtypes of GABAergic neurons in mouse visual cortex identified by triple immunostaining. Front Neuroanat 1:3.

Halabisky B, Shen F, Huguenard JR, Prince DA (2006) Electrophysiological classification of somatostatin-positive interneurons in mouse sensorimotor cortex. J Neurophysiol 96:834-845.

Holmgren C, Harkany T, Svennenfors B, Zilberter Y (2003) Pyramidal cell communication within local networks in layer $2 / 3$ of rat neocortex. J Physiol 551:139-153.

Hooks BM, Hires SA, Zhang YX, Huber D, Petreanu L, Svoboda K, Shepherd GMG (2011) Laminar analysis of excitatory local circuits in vibrissal motor and sensory cortical areas. PLoS Biol 9:e1000572.

Hull C, Adesnik H, Scanziani M (2009) Neocortical disynaptic inhibition requires somatodendritic integration in interneurons. J Neurosci 29:8991-8995.

Isomura Y, Harukuni R, Takekawa T, Aizawa H, Fukai T (2009) Microcircuitry coordination of cortical motor information in self-initiation of voluntary movements. Nat Neurosci 12:1586-1593.

Kaneko T, Cho R, Li Y, Nomura S, Mizuno N (2000) Predominant information transfer from layer III pyramidal neurons to corticospinal neurons. J Comp Neurol 423:52-65.

Kapfer C, Glickfeld LL, Atallah BV, Scanziani M (2007) Supralinear increase of recurrent inhibition during sparse activity in the somatosensory cortex. Nat Neurosci 10:743-753.

Kätzel D, Zemelman BV, Buetfering C, Wölfel M, Miesenböck G (2011) The columnar and laminar organization of inhibitory connections to neocortical excitatory cells. Nat Neurosci 14:100-107.

Kaufman MT, Churchland MM, Santhanam G, Yu BM, Afshar A, Ryu SI, Shenoy KV (2010) Roles of monkey premotor neuron classes in movement preparation and execution. J Neurophysiol 104:799-810.

Keller A (1993) Intrinsic synaptic organization of the motor cortex. Cereb Cortex 3:430-441.

Kiritani T, Wickersham IR, Seung HS, Shepherd GM (2012) Hierarchical con- nectivity and connection-specific dynamics in the corticospinal-corticostriatal microcircuit in mouse motor cortex. J Neurosci 32:4992-5001.

Krook-Magnuson E, Varga C, Lee SH, Soltesz I (2012) New dimensions of interneuronal specialization unmasked by principal cell heterogeneity. Trends Neurosci 35:175-184.

Lam YW, Sherman SM (2011) Functional organization of the thalamic input to the thalamic reticular nucleus. J Neurosci 31:6791-6799.

Lefort S, Tomm C, Floyd Sarria JC, Petersen CC (2009) The excitatory neuronal network of the $\mathrm{C} 2$ barrel column in mouse primary somatosensory cortex. Neuron 61:301-316.

Ma Y, Hu H, Berrebi AS, Mathers PH, Agmon A (2006) Distinct subtypes of somatostatin-containing neocortical interneurons revealed in transgenic mice. J Neurosci 26:5069-5082.

Markram H, Toledo-Rodriguez M, Wang Y, Gupta A, Silberberg G, Wu C (2004) Interneurons of the neocortical inhibitory system. Nat Rev Neurosci 5:793-807.

Merchant H, Naselaris T, Georgopoulos AP (2008) Dynamic sculpting of directional tuning in the primate motor cortex during three-dimensional reaching. J Neurosci 28:9164-9172.

Morishima M, Kawaguchi Y (2006) Recurrent connection patterns of corticostriatal pyramidal cells in frontal cortex. J Neurosci 26:4394-4405.

Murthy VN, Fetz EE (1992) Coherent 25- to 35-Hz oscillations in the sensorimotor cortex of awake behaving monkeys. Proc Natl Acad Sci U S A 89:5670-5674.

Neymotin SA, Jacobs KM, Fenton AA, Lytton WW (2011) Synaptic information transfer in computer models of neocortical columns. J Comput Neurosci 30:69-84.

Oliva AA Jr, Jiang M, Lam T, Smith KL, Swann JW (2000) Novel hippocampal interneuronal subtypes identified using transgenic mice that express green fluorescent protein in GABAergic interneurons. J Neurosci 20:3354-3368.

Osakada F, Mori T, Cetin AH, Marshel JH, Virgen B, Callaway EM (2011) New rabies virus variants for monitoring and manipulating activity and gene expression in defined neural circuits. Neuron 71:617-631.

Oswald AM, Doiron B, Rinzel J, Reyes AD (2009) Spatial profile and differential recruitment of $\mathrm{GABA}_{\mathrm{B}}$ modulate oscillatory activity in auditory cortex. J Neurosci 29:10321-10334.

Otsuka T, Kawaguchi Y (2009) Cortical inhibitory cell types differentially form intralaminar and interlaminar subnetworks with excitatory neurons. J Neurosci 29:10533-10540.

Packer AM, Yuste R (2011) Dense, unspecific connectivity of neocortical parvalbumin-positive interneurons: a canonical microcircuit for inhibition? J Neurosci 31:13260-13271.

Petreanu L, Huber D, Sobczyk A, Svoboda K (2007) Channelrhodopsin-2assisted circuit mapping of long-range callosal projections. Nat Neurosci 10:663-668.

Phillips CG (1959) Actions of antidromic pyramidal volleys on single Betz cells in the cat. Q J Exp Physiol Cogn Med Sci 44:1-25.

Reiner A, Hart NM, Lei W, Deng Y (2010) Corticostriatal projection neurons- dichotomous types and dichotomous functions. Front Neuroanat $4: 142$.

Rudy B, Fishell G, Lee S, Hjerling-Leffler J (2011) Three groups of interneurons account for nearly $100 \%$ of neocortical GABAergic neurons. Dev Neurobiol 71:45-61.

Schubert D, Kötter R, Luhmann HJ, Staiger JF (2006) Morphology, electrophysiology and functional input connectivity of pyramidal neurons characterizes a genuine layer Va in the primary somatosensory cortex. Cereb Cortex 16:223-236.

Sheets PL, Suter BA, Kiritani T, Chan CS, Surmeier DJ, Shepherd GMG (2011) Corticospinal-specific HCN expression in mouse motor cortex: $I_{\mathrm{h}}$-dependent synaptic integration as a candidate microcircuit mechanism involved in motor control. J Neurophysiol 106:2216-2231.

Shepherd GMG (2011) Circuit mapping by ultraviolet uncaging of glutamate. In: Imaging in neuroscience: a laboratory manual (Helmchen F, Konnerth A, Yuste R, eds), pp 417-427. Cold Spring Harbor, NY: Cold Spring Harbor Laboratory.

Shepherd GMG, Pologruto TA, Svoboda K (2003) Circuit analysis of experience-dependent plasticity in the developing rat barrel cortex. Neuron 38:277-289.

Silberberg G, Markram H (2007) Disynaptic inhibition between neocortical pyramidal cells mediated by Martinotti cells. Neuron 53:735-746.

Stefanis C, Jasper H (1964a) Intracellular microelectrode studies of anti- 
dromic responses in cortical pyramidal tract neurons. J Neurophysiol $27: 828-854$.

Stefanis C, Jasper H (1964b) Recurrent collateral inhibition in pyramidal tract neurons. J Neurophysiol 27:855-877.

Suter BA, O'Connor T, Iyer V, Petreanu LT, Hooks BM, Kiritani T, Svoboda K, Shepherd GMG (2010) Ephus: multipurpose data acquisition software for neuroscience experiments. Front Neurosci Methods 4:1-12.

Tanaka YH, Tanaka YR, Fujiyama F, Furuta T, Yanagawa Y, Kaneko T (2011) Local connections of layer 5 GABAergic interneurons to corticospinal neurons. Front Neural Circuits 5:12.

Thomson AM, Lamy C (2007) Functional maps of neocortical local circuitry. Front Neurosci 1:19-42.

Thomson AM, West DC, Wang Y, Bannister AP (2002) Synaptic connections and small circuits involving excitatory and inhibitory neurons in layers $2-5$ of adult rat and cat neocortex: triple intracellular recordings and biocytin labelling in vitro. Cereb Cortex 12:936-953.

Vigneswaran G, Kraskov A, Lemon RN (2011) Large identified pyramidal cells in macaque motor and premotor cortex exhibit "thin spikes": implications for cell type classification. J Neurosci 31:14235-14242.

Weiler N, Wood L, Yu J, Solla SA, Shepherd GMG (2008) Top-down laminar organization of the excitatory network in motor cortex. Nat Neurosci 11:360-366.

Wickersham IR, Finke S, Conzelmann KK, Callaway EM (2007) Retrograde neuronal tracing with a deletion-mutant rabies virus. Nat Methods 4:47-49.
Wickersham IR, Sullivan HA, Seung HS (2010) Production of glycoproteindeleted rabies viruses for monosynaptic tracing and high-level gene expression in neurons. Nat Protoc 5:595-606.

Wood L, Shepherd GMG (2010) Synaptic circuit abnormalities of motorfrontal layer $2 / 3$ pyramidal neurons in a mutant mouse model of Rett syndrome. Neurobiol Dis 38:281-287.

Wood L, Gray NW, Zhou Z, Greenberg ME, Shepherd GMG (2009) Synaptic circuit abnormalities of motor-frontal layer $2 / 3$ pyramidal neurons in an RNA interference model of methyl-CpG-binding protein 2 deficiency. J Neurosci 29:12440-12448.

Xu X, Callaway EM (2009) Laminar specificity of functional input to distinct types of inhibitory cortical neurons. J Neurosci 29:70-85.

Xu X, Roby KD, Callaway EM (2010) Immunochemical characterization of inhibitory mouse cortical neurons: three chemically distinct classes of inhibitory cells. J Comp Neurol 518:389-404.

Yoshimura Y, Callaway EM (2005) Fine-scale specificity of cortical networks depends on inhibitory cell type and connectivity. Nat Neurosci 8:1552-1559.

Yu J, Anderson CT, Kiritani T, Sheets PL, Wokosin DL, Wood L, Shepherd GMG (2008) Local-circuit phenotypes of layer 5 neurons in motorfrontal cortex of YFP-H mice. Front Neural Circuits 2:6.

Zhu J, Jiang M, Yang M, Hou H, Shu Y (2011) Membrane potentialdependent modulation of recurrent inhibition in rat neocortex. PLoS Biol 9:e1001032. 